\title{
Ionic conductivity in multiply substituted ceria-based electrolytes
}

\author{
Alice V. Coles-Aldridge, Richard T. Baker* \\ EaStChem, School of Chemistry, University of St. Andrews \\ North Haugh, St Andrews, Fife, KY16 9ST, United Kingdom
}

*Corresponding author. Tel.: +44 1334 463899; Fax: +44 1334 463808; E-mail: rtb5@st-andrews.ac.uk

Keywords: ceria, doping, ionic conductivity, fuel cells, Solid Oxide Fuel Cells, rare earth

\begin{abstract}
Cerias, appropriately doped with trivalent rare earth ions, have high oxide ion conductivity and are attractive SOFC (solid oxide fuel cell) electrolytes. Here, seven compositions of $\mathrm{Ce}_{0.8} \mathrm{Sm}_{x} \mathrm{Gd}_{y} \mathrm{Nd}_{z} \mathrm{O}_{1.9}$ (where $x, y$ and $z=0.2,0.1,0.0667$ or 0 and $x+y+z=0.2$ ) are synthesised using a low temperature method in order to determine the effect of multiple doping on microstructure and conductivity. Analysis using scanning and transmission electron microscopy, inductively coupled plasma mass spectrometry, X-ray diffraction and impedance spectroscopy is carried out. Crystallite sizes are determined in the powders and relative densities and grain size distributions were obtained in sintered pellets. Total, bulk and grain boundary conductivities are obtained using impedance spectroscopy and corresponding activation energies and enthalpies of ion migration and defect association are calculated. The highest total conductivity observed at $600{ }^{\circ} \mathrm{C}$ is $1.80 \mathrm{Sm}^{-1}$ for $\mathrm{Ce}_{0.8} \mathrm{Sm}_{0.1} \mathrm{Gd}_{0.1} \mathrm{O}_{1.9}$ and an enhancement effect on conductivity for this combination of codopants between $300{ }^{\circ} \mathrm{C}$ and $700{ }^{\circ} \mathrm{C}$ relative to the singly doped compounds $-\mathrm{Ce}_{0.8} \mathrm{Sm}_{0.2} \mathrm{O}_{1.9}$ and $\mathrm{Ce}_{0.8} \mathrm{Gd}_{0.2} \mathrm{O}_{1.9}$ - is seen. This has interesting implications for application as SOFC electrolytes, especially at intermediate temperatures.
\end{abstract}




\section{Introduction}

The clean and efficient generation of electricity is a pressing global challenge. Fuel cells convert chemical energy from a gaseous fuel and oxidant directly into electrical work and SOFCs in particular exhibit high efficiencies, low pollutant emissions, fuel flexibility and suitability for Combined Heat and Power applications.[1] Therefore, SOFCs are likely to play an important part in energy conversion in the near future and are being developed for commercial applications ranging from domestic units to small power stations.[2][3]'[4] So far, widespread use of SOFCs has been inhibited by their high operating temperatures of typically 800 to $1000^{\circ} \mathrm{C}$.[5] A move to Intermediate temperature (IT)-SOFCs, which operate between 500 and $750^{\circ} \mathrm{C}$ - is desirable in order to widen the range of structural and functional materials that can be used, and reduce energy usage, electrode sintering, interfacial diffusion between electrolyte and electrodes and thermal stress.[6]'[7] However, the lower ionic conductivity of the electrolyte at these lower temperatures can limit the performance of IT-SOFCs. Therefore, optimising electrolyte design to increase conductivity to acceptable levels at these temperatures becomes central.

Electrolytes based on ceria demonstrate higher oxide ion conductivity at IT than YSZ (yttria-stabilised zirconia), the most commonly used electrolyte in SOFCs. A structure containing a large number of interconnected, equivalent and partially occupied sites for the oxide ion is required for high intrinsic (or 'bulk') ionic conductivity. This is achieved by aliovalent doping of the material - the partial substitution of $\mathrm{Ce}^{4+}$ ions by tri- or divalent cations in order to create oxygen vacancies to maintain charge neutrality.[8] The relatively facile migration of these vacancies in the cubic anionic sublattice at elevated temperatures then gives rise to fast ionic transport through the electrolyte.[9]

Reports have shown that ceria doped with certain trivalent rare earth ions gives higher bulk ionic conductivity than those doped with other elements.[10] The concept of matching the size of the trivalent dopant ion to that of $\mathrm{Ce}^{4+}(0.97$ $\AA ̊$ ) in order to minimise both strain and activation energy for oxygen vacancy diffusion, $E_{a}$, is an important consideration.[11]'[12]'[13] In this approach, to optimise bulk ionic conductivity, the repulsive elastic (related to dopant radius) and attractive electronic components of the interaction between vacancies and dopant ions should balance. According to research by Andersson et al using ab initio methods, this is the case for a hypothetical atomic number between $61(\mathrm{Pm})$ and $62(\mathrm{Sm})$. Pm is radioactive, so a combination of alternative lanthanide dopant ions with 
an average atomic number between 61 and 62 was proposed to optimise bulk ionic conductivity in electrolytes based on ceria.[14] This hypothesis was investigated experimentally in work by Omar et al in which $\mathrm{Sm}^{3+}$ and $\mathrm{Nd}^{3+}$ were selected to form electrolytes of composition, $\mathrm{Sm}_{x / 2} \mathrm{Nd}_{x / 2} \mathrm{Ce}_{1-x} \mathrm{O}_{2-\delta}$ (with $\mathrm{x}=0.01-0.2$ ), in which the average atomic number of the dopants was therefore 61 . The authors interpreted the adherence of this compositional series to a linear relationship between $\mathbf{x}$ and unit cell parameter, a (Vegard's law) as an indication that less short-range ordering of oxygen vacancies and dopant cations occurred in these materials than in singly-doped materials, such as the series, $\mathrm{Nd}_{x} \mathrm{Ce}_{1-x} \mathrm{O}_{2-\delta}$, reported by Stephens and Kilner which displayed a second-order dependence.[15] This lack of defect ordering was proposed to result from a similarity in energy of the sites available to host oxygen ion vacancies which was given in turn as the reason for improved ionic conductivity. At $550{ }^{\circ} \mathrm{C}, \mathrm{Sm}_{0.05} \mathrm{Nd}_{0.05} \mathrm{Ce}_{0.10} \mathrm{O}_{2-\delta}$ was found to have a higher bulk ionic conductivity than the widely used, analogous composition, $\mathrm{Gd}_{0.10} \mathrm{Ce}_{0.90} \mathrm{O}_{2-\delta}$, so supporting the hypothesis of Andersson described above.[16]

The ideal average atomic number between 61 and 62 also corresponds to a critical dopant ionic radius $\left(r_{c}\right)$. Omar et $a l$ ensured that the average dopant ionic radius of the synthesised $\mathrm{Lu}_{x} \mathrm{Nd}_{y} \mathrm{Ce}_{1-x-y} \mathrm{O}_{2-y}$ matched $r_{C}$ for all compositions in order to investigate the effect of elastic strain in the lattice on bulk ionic conductivity.[17] It was found that the elastic strain in the doubly doped system was negligible compared to the parent singly doped systems and that the bulk ionic conductivity was higher for the doubly doped system than for the corresponding singly doped systems. Therefore, it was concluded that co-doping based on $r_{C}$ can lead to increased conductivity for ceria electrolytes. In a later paper, however, the same authors concluded that $r_{C}$ alone was insufficient to fully explain the conductivity of doped cerias.[18]

Wang and co-workers observed a higher total conductivity for $\mathrm{Ce}_{0.85} \mathrm{Gd}_{0.15-y} \mathrm{Sm}_{y} \mathrm{O}_{1.925}(0.05 \leq y \leq 0.1)$ than for $\mathrm{Ce}_{0.85} \mathrm{Gd}_{0.15} \mathrm{O}_{1.925}$ or $\mathrm{Ce}_{0.85} \mathrm{Sm}_{0.15} \mathrm{O}_{1.925}$ between 500 and $700{ }^{\circ} \mathrm{C}$. .[19] This was attributed to suppression of the ordering of oxygen vacancies and hence a lower activation energy for the co-doped ceria than for the singly doped ceria. Anirban and co-workers observed that ceria co-doped with $\mathrm{Gd}^{3+}$ and $\mathrm{Nd}^{3+}$ exhibited a slight increase in bulk conductivity and a more significant increase in grain boundary conductivity compared to the singly doped specimens with the same dopant concentration with the effect of co-doping increasing at $600{ }^{\circ} \mathrm{C}$ and above.[20] Liu and coworkers found that, of all the $\mathrm{Sm}^{3+}$ and $\mathrm{Nd}^{3+}$ co-doped and singly doped compositions investigated, the highest total ionic conductivity was observed for $\mathrm{Ce}_{0.8} \mathrm{Sm}_{0.1} \mathrm{Nd}_{0.1} \mathrm{O}_{1.9}$.[21] These studies show that co-doping can have beneficial effects on the conductivity of ceria-based electrolytes. However, computational work by Burbano and co-workers 
predicted that the bulk ionic conductivity of co-doped systems lies within the range spanned by the singly doped materials between 600 and $1000^{\circ} \mathrm{C}$.[22] Whether the co-doping of ceria has a synergistic, detrimental or averaging effect on ionic conductivity will determine which compositions emerge as the most promising ceria-based electrolytes and whether these can be successfully applied in IT-SOFCs.

There is no overall consensus on the best dopant or combination of dopants for ceria-based electrolytes. Therefore, in this work, seven nanopowders with the composition $\mathrm{Ce}_{0.8} \mathrm{Sm}_{x} \mathrm{Gd}_{y} \mathrm{Nd}_{z} \mathrm{O}_{1.9}$ where $x, y$ and $z=0.2,0.1,0.667$ or 0 and $x+y+z=0.2$ were synthesised. The chemical composition, powder nanostructure and crystal phase of these products were studied as were the microstructure and total, bulk and grain boundary ionic conductivities of the dense electrolyte pellets prepared from these powders. The results and analyses were cross-compared to gain insight into the parameters determining favourable performance in these materials.

\section{Experimental}

Seven compositions of $\mathrm{Ce}_{0.8} \mathrm{Sm}_{x} \mathrm{Gd}_{y} \mathrm{Nd}_{z} \mathrm{O}_{1.9}$ were prepared where $x, y$ and $z=0.2,0.1,0.667$ or 0 and $x+y+z=0.2$ (see Table 1). $0.1 \mathrm{~mol} \mathrm{dm}^{-3}$ solutions were made by dissolving stoichiometric amounts of metal nitrate hexahydrates, $\mathrm{Ce}\left(\mathrm{NO}_{3}\right)_{3} .6 \mathrm{H}_{2} \mathrm{O}$ (Acros Organics, $99.5 \%$ ), $\mathrm{Sm}\left(\mathrm{NO}_{3}\right)_{3} .6 \mathrm{H}_{2} \mathrm{O}$ (Acros Organics, $99.9 \%$ ), $\mathrm{Gd}\left(\mathrm{NO}_{3}\right)_{3} .6 \mathrm{H}_{2} \mathrm{O}$ (Acros Ogranics, $99.9 \%$ ) and $\mathrm{Nd}\left(\mathrm{NO}_{3}\right)_{3} .6 \mathrm{H}_{2} \mathrm{O}$ (Aldrich, 99.9\%) separately in deionised water. They were stirred for $3 \mathrm{~h}$ to homogenise before being combined. A $0.2 \mathrm{~mol} \mathrm{dm}^{-3}$ citric acid solution was made by dissolving anhydrous citric acid (Alfa Aesar, $99.5 \%$ in deionised water and stirring for $3 \mathrm{~h}$ to homogenise prior to being added to the metal cation solution in the ratio of one mole of total metal cations to two moles of citrate. The resulting solution was stirred for $12 \mathrm{~h}$ to achieve homogenisation, heated to $80^{\circ} \mathrm{C}$ and maintained under stirring for $24 \mathrm{~h}$. Evolution of steam and gas resulted in a gel and finally a solid yellow foam. Thermal decomposition of the foam was carried out in a muffle furnace at $250{ }^{\circ} \mathrm{C}$ for 2 $\mathrm{h}$ and the resulting powder was calcined in a muffle furnace at $500{ }^{\circ} \mathrm{C}$ for $2 \mathrm{~h}$. Heating and cooling rates were $2.5^{\circ} \mathrm{C}$ $\min ^{-1}$ and $5^{\circ} \mathrm{C} \min ^{-1}$ respectively. The powders were dry ground for $1 \mathrm{~h}$ at $400 \mathrm{rpm}$ in a planetary ball mill (Fritsch Pulverisette 7)[23] using Nylon jars and $10 \mathrm{~mm}$ diameter zirconia balls as the grinding medium and a powder to ball weight ratio of 1:10. It was necessary to suspend the ball milling process every 15 minutes in order to displace the powder from the walls of the jar. The seven resulting nanopowder compositions underwent detailed characterisation. 


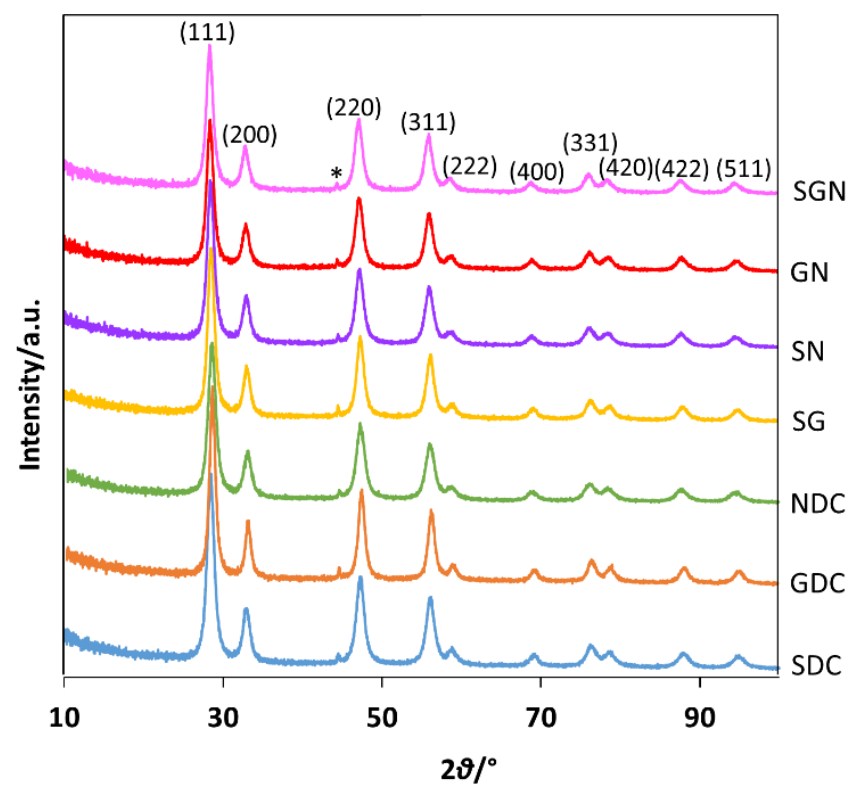

Figure 1. XRD patterns for powder samples of $\mathrm{Ce}_{0.8} \mathrm{Sm}_{x} \mathrm{Gd}_{y} \mathrm{Nd}_{z} \mathrm{O}_{1.9}$ for all compositions. *Small peak at about $45^{\circ}$ is due to the sample holder (main peak of Fe).

To make sintered electrolyte pellets, the powders were uniaxially pressed at $200 \mathrm{MPa}$ in a $25 \mathrm{~mm}$ (for impedance spectroscopy) or $10 \mathrm{~mm}$ (for examination using SEM, scanning electron microsopy) diameter, cylindrical stainless steel dye. The pellets were sintered at $1450{ }^{\circ} \mathrm{C}$ for $4 \mathrm{~h}$ with a heating rate of $2{ }^{\circ} \mathrm{C} \min ^{-1}$ and a cooling rate of $4{ }^{\circ} \mathrm{C} \mathrm{min}-1$ in accordance with the method used previously for the synthesis of samarium doped ceria (SDC).[24] The sintered pellets were polished using 600 and 1200 grade silicon carbide paper and $6 \mu \mathrm{m}$ diamond paste (and $3 \mu \mathrm{m}$ diamond paste for the SEM pellets) resulting in a mirror finish.

XRD (X-ray diffraction) analysis of the samples was carried out using a PANalytical Empyrean diffractometer with $\mathrm{Cu}$ $\mathrm{K \alpha}_{1}$ monochromatic radiation. The external standard used was high-grade silicon powder which allowed correction for instrumental broadening. Data were acquired at room temperature by scanning $2 \vartheta$ from $10^{\circ}$ to $100^{\circ}$ with a step size of $0.017^{\circ}$ and a step time of $0.95 \mathrm{~s}$. The XRD patterns were fitted using Rietveld operations in the High Score Plus programme.

The nanopowders were dissolved in concentrated nitric acid in Teflon-lined autoclaves at $160{ }^{\circ} \mathrm{C}$ for $8 \mathrm{~h}$ for analysis by ICP-MS (inductively coupled plasma- mass spectrometry) using an Agilent 7500ce with Ar gas flows of $0.82 \mathrm{~L} \mathrm{~min}{ }^{-1}$ (carrier) and $0.2 \mathrm{~L} \mathrm{~min}^{-1}$ (makeup). Sample solutions were taken into the nebuliser at a rate of approximately $1.0 \mathrm{~mL}$ $\mathrm{min}^{-1}$. Three runs for each sample were carried out and each mass was analysed in fully quantitative mode (three points per unit mass). ${ }^{140} \mathrm{Ce},{ }^{157} \mathrm{Gd},{ }^{146} \mathrm{Nd}$ and ${ }^{147} \mathrm{Sm}$ were analysed in no gas mode. Calibration standards were prepared 
using single element $1000 \mathrm{mg} \mathrm{L}^{-1}$ stock solutions for $\mathrm{Ce}, \mathrm{Gd}, \mathrm{Nd}$ and $\mathrm{Sm}\left(\mathrm{Qmx}\right.$ ), diluted with $2 \% \mathrm{HNO}_{3} \mathrm{v} / \mathrm{v}$ (Aristar grade, Merck).

SEM images of the pellets were obtained using a JEOL JSM-6700F instrument equipped with a field emission gun at $5.0 \mathrm{kV}$ and were used to carry out statistical grain area analyses on each sample where the areas of many grains (> 400) were measured using ImageJ software. For SEM polished pellets were thermally etched at $1400{ }^{\circ} \mathrm{C}$, employing a dwell time of $1 \mathrm{~min}$. and identical ramp rates to those used in the sintering process. Samples were gold-coated to reduce charging. A JEOL JEM-2011 instrument was used to acquire TEM (transmission electron microscope) images for crystallite size analysis. Samples were prepared by submerging $3 \mathrm{~mm}$ holey carbon $\mathrm{Cu}$ grids in an ultrasonicated dispersion of the powder in acetone. The Cu grids were dried overnight.

The dimensions and masses of the sintered pellets were used to calculate their densities. Relative density values were obtained by dividing these density values by the corresponding theoretical density, $\rho_{X R D}$, calculated using Equation 1 from the crystallographic information obtained by XRD, where $M_{i}$ is the atomic mass of element $i ; x, y$ and $z=0.2,0.1$, 0.667 or 0 (and $x+y+z=0.2$ ) and $u$ is the atomic mass unit and $V$ is the unit cell volume.

$$
\rho_{X R D}=\frac{u \times\left(\left(\left(0.8 \times M_{C e}\right)+\left(x \times M_{S m}\right)+\left(y \times M_{G d}\right)+\left(z \times M_{N d}\right)\right) \times 4\right)+\left(\left(0.9 \times M_{O}\right) \times 8\right)}{V}
$$

Two-electrode impedance spectroscopy was performed on the electrolyte pellets using a Solartron 1260 FRA instrument. Electrodes were deposited by screen-printing Pt ink (inorganic-free, Engelhardt) on each side of the pellets and firing at $1000{ }^{\circ} \mathrm{C}$ for $1 \mathrm{~h}$ with heating and cooling rates of $2^{\circ} \mathrm{C} \mathrm{min}^{-1}$. The resulting cells were placed in a tube furnace and impedance measurements were carried out under flowing pre-dried, synthetic air $\left(50 \mathrm{ml} \mathrm{min} \mathrm{m}^{-1}\right)$ at intervals of $50{ }^{\circ} \mathrm{C}$ between $150-900{ }^{\circ} \mathrm{C}$, during both heating and cooling ramps. An A.C. voltage of $100 \mathrm{mV}\left(250^{\circ} \mathrm{C}-900^{\circ} \mathrm{C}\right)$ or $500 \mathrm{mV}\left(150^{\circ} \mathrm{C}-200^{\circ} \mathrm{C}\right)$ was applied and the frequency was swept from $10 \mathrm{MHz}$ to $1 \mathrm{~Hz}$. At each measurement temperature, multiple spectra were recorded until there were no variations between them. ZView software (Scribner Associates, Inc.) was used to analyse the impedance spectra.

\section{Results and Discussion}




\subsection{Powder Characterisation}

After calcination, the products consisted of voluminous fragile, papery structures which yielded very, pale yellow nanopowders after milling. XRD patterns of the seven $\mathrm{Ce}_{0.8} \mathrm{Sm}_{x} \mathrm{Gd}_{y} \mathrm{Nd}_{z} \mathrm{O}_{1.9}$ nanopowders are given in Figure 1. All peaks could be assigned to the cubic fluorite $F m-3 m$ crystal structure. There was no evidence of any other phases indicating that the powders were homogeneous and that the dopants were soluble in the cerium oxide lattice. Figure 2 presents lattice parameter, crystallite size and relative density as a function of average cation ionic radius. The lattice parameter (a, determined by Rietveld refinement of the XRD data) increased from $5.4244 \AA\left(\mathrm{Ce}_{0.8} \mathrm{Gd}_{0.2} \mathrm{O}_{1.9}\right)$ to $5.4446 \AA$ $\left(\mathrm{Ce}_{0.8} \mathrm{Nd}_{0.2} \mathrm{O}_{1.9}\right)$. This showed a strong linear dependence when plotted against the average ionic radii of the trivalent dopant ions for each composition (Figure 2a) indicating that Vegard's Law was obeyed in these materials, in spite of the presence of different cation combinations.[25] Table 1 summarises the lattice parameters and the average crystallite diameters $\left(D_{X R D}\right)$ of the seven powders obtained from the XRD data. Crystallite diameter was calculated from the extent of line broadening of the principal (111) diffraction peak using the Scherrer equation.[26] It decreased as the average ionic radius of the dopants increased, from $93 \AA$ for $\mathrm{Ce}_{0.8} \mathrm{Gd}_{0.2} \mathrm{O}_{1.9}$ to $55 \AA$ for $\mathrm{Ce}_{0.8} \mathrm{Nd}_{0.2} \mathrm{O}_{1.9}$ (Figure $2 \mathrm{~b}$ ).

These values are comparable to those from previous work using the same synthesis method.[24] TEM images of each of the seven samples were used to calculate the average diameter of the individual crystallites, $D_{\text {TEM, }}$ (see Table 1 , Figure $2 \mathrm{~b}$ and Figure S1 in Electronic Supplementary Information (ESI)). This showed a similar trend to $D_{X R D}$, although at higher values. This difference between the $D_{X R D}$ and the $D_{T E M}$ values is attributed to the difficulty of reliably identifying very small nanocrystals in the TEM, especially since the crystallites were arranged in loosely agglomerated clusters - and therefore overlapping in the images - for all compositions. Individual particles were seen by high resolution TEM to have excellent crystallinity with no evidence of crystallites containing multiple nanodomains. The decreasing trend in crystallite size with increasing average ionic radius may be related to decreasing ionic diffusion rates as cation size increased. 

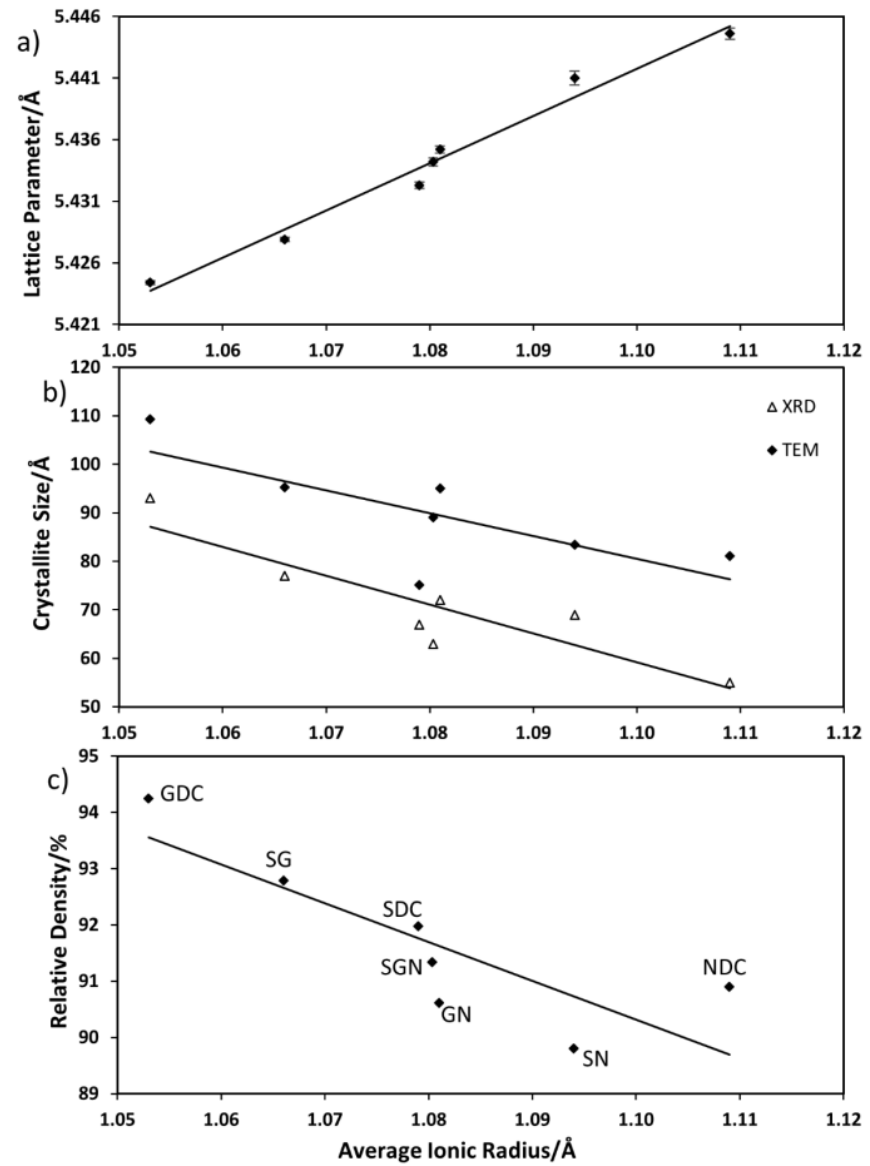

Figure 2. Dependence on average ionic radius of dopant ions in $\mathrm{Ce}_{0.8} \mathrm{Sm}_{x} \mathrm{Gd}_{y} \mathrm{Nd}_{z} \mathrm{O}_{1.9}$ of a) lattice parameter obtained from powder XRD; b) average crystallite size calculated from powder XRD data and TEM images; $\mathrm{C}$ ) relative density of pellets sintered at $1450^{\circ} \mathrm{C}$ for $4 \mathrm{~h}$. The best fit lines are added as guides to the eye.

ICP-MS was used for elemental analysis and the values are reported in Table 2 as cation \% with associated errors (one standard deviation). No major impurities were identified in any of the compositions. However, there are discrepancies between the nominal stoichiometries and the ICP-MS results. Although the dopant concentrations are slightly higher than expected, the total dopant concentration is close to constant for all samples meaning the oxygen vacancy concentration (which is directly determined by the dopant concentration) is expected to be near-identical in each case. Therefore, comparisons between samples can be made based on the different individual dopant concentrations and identities. Unexpected Sm, Gd or Nd in a sample is likely to have been introduced from the starting nitrates (which were also analysed using ICP-MS). In the most important case, the remaining $0.5 \%$ in the $99.5 \%$ pure cerium nitrate hexahydrate was found to primarily consist of a gadolinium compound. This led to the slight excesses seen for this particular dopant. 


\subsection{Pellet Characterisation}

Pellets were sintered at $1450^{\circ} \mathrm{C}$ for $4 \mathrm{~h}$ because this is close to the regime found to give maximum conductivity in SDC in previous work by Kosinski and Baker which also used the citrate-nitrate synthesis method.[24] The relative densities ranged from $89.8 \%$ for $\mathrm{Ce}_{0.8} \mathrm{Sm}_{0.1} \mathrm{Nd}_{0.1} \mathrm{O}_{1.9}$ to $94.3 \%$ for $\mathrm{Ce}_{0.8} \mathrm{Gd}_{0.2} \mathrm{O}_{1.9}$. There is a general decrease in relative density with increasing average ionic radius of the dopant lanthanides comprising the sample (Figure 2c). The rate of cation diffusion at the high temperatures of synthesis and sintering is likely to decrease as average cation size increases. This may explain the similar decreasing trend in crystallite size (see above). Both these trends - of decreasing crystallite size and decreasing cation diffusion rate with increasing cation size - may contribute to limit the degree of sintering and cause the corresponding decrease in relative density..

Figure 3 shows SEM images of the fired samples after polishing and thermal etching. Interlocking grains of typical, approximately hexagonal shape were observed. Grain areas are presented as normalised distribution histograms next to the corresponding images in Figure 3. These exhibit an approximately log-normal distribution of grain sizes with similar modal grain areas for each sample showing that grain growth was normal for all samples.[24] Average grain sizes were not found to correlate with crystallite size, relative density nor the average ionic radius of the trivalent dopants (Figure 4) and grain areas ranged from $0.249 \mu \mathrm{m}^{2}$ for $\mathrm{Ce}_{0.8} \mathrm{Gd}_{0.2} \mathrm{O}_{1.9}$ to $0.414 \mu \mathrm{m}^{2}$ for $\mathrm{Ce}_{0.8} \mathrm{Sm}_{0.1} \mathrm{Gd}_{0.1} \mathrm{O}_{1.9}$. This contrasts with the trends in powder crystallite diameter and relative density of the sintered pellet, both of which showed a general decrease with increasing average ionic radius of the dopants. In the SEM images all samples show a small amount of porosity, accounting for the lower than expected relative density of all samples. Grain growth could have been limited by these pores pinning the grain boundaries. This differs from the results of Kosinski and Baker where sintering conditions of $1450{ }^{\circ} \mathrm{C}$ for $4 \mathrm{~h}$ produced samples with lower porosity and larger grains.[24] There is a small possibility that the higher porosity than expected for these samples is due to oversintering. This phenomenon was reported by Liu et al[21] for the composition $\mathrm{Ce}_{0.8} \mathrm{Sm}_{0.1} \mathrm{Nd}_{0.1} \mathrm{O}_{1.9}$ when sintered for $5 \mathrm{~h}$ at $1500^{\circ} \mathrm{C}$ and (more markedly) $1600^{\circ} \mathrm{C}$ and proposed by Kosinski and Baker[24] for sintering conditions of $1450{ }^{\circ} \mathrm{C}$ for $6 \mathrm{~h}$. However, it should be noted that the grains were larger in these studies than in the present contribution. 
a)

b)
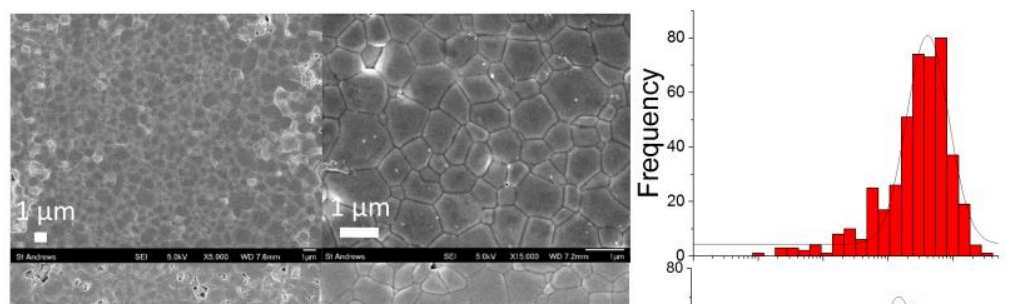

c)

d)
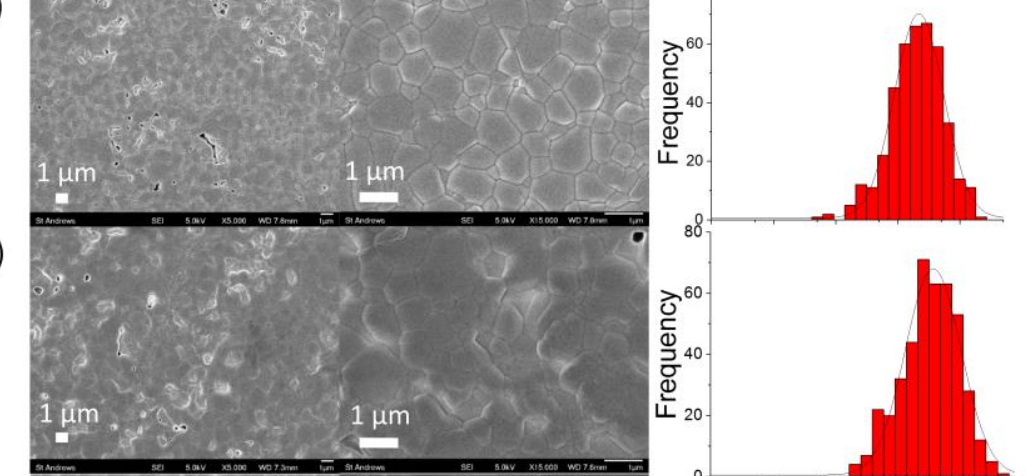

e)

f)
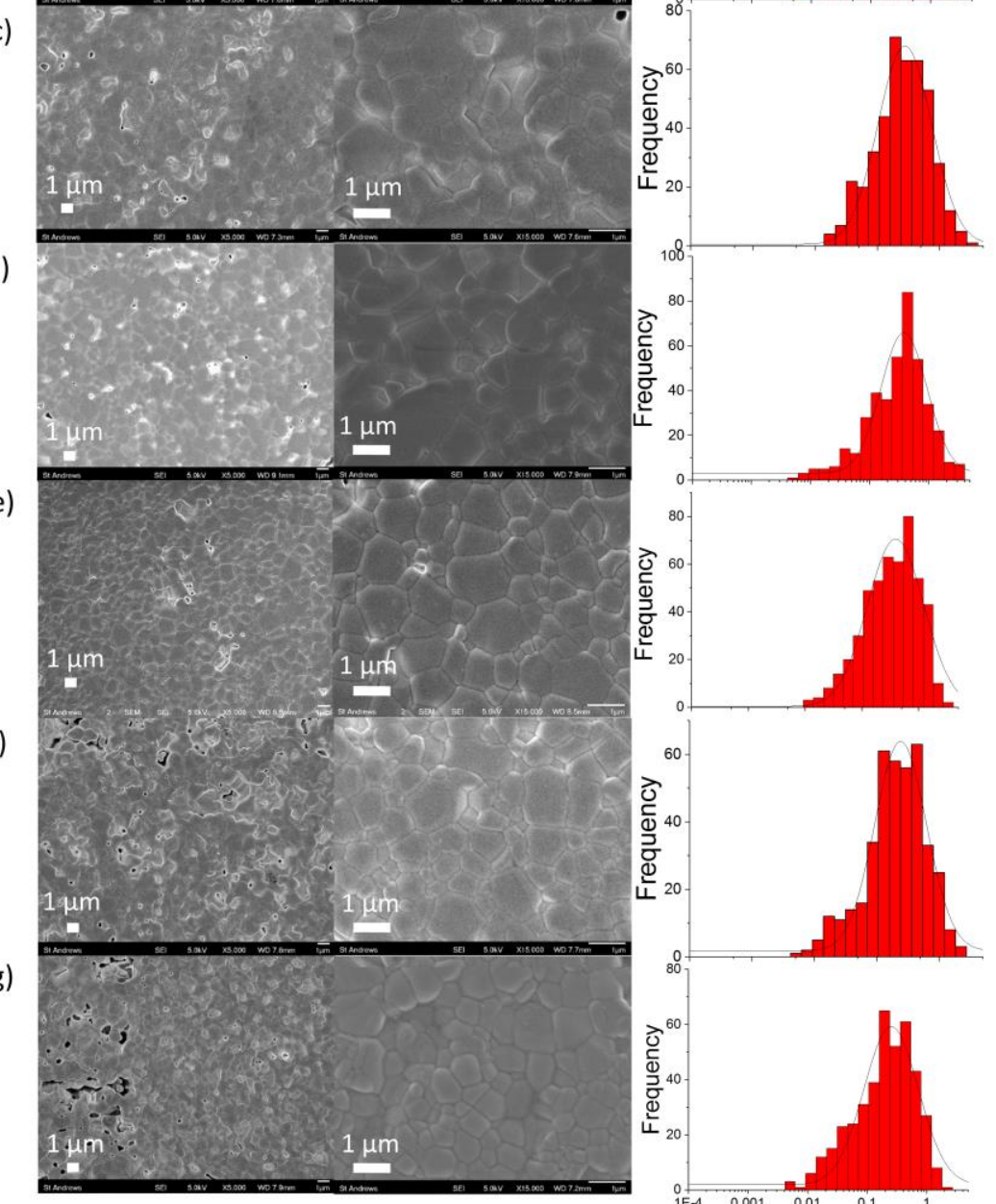

(1)
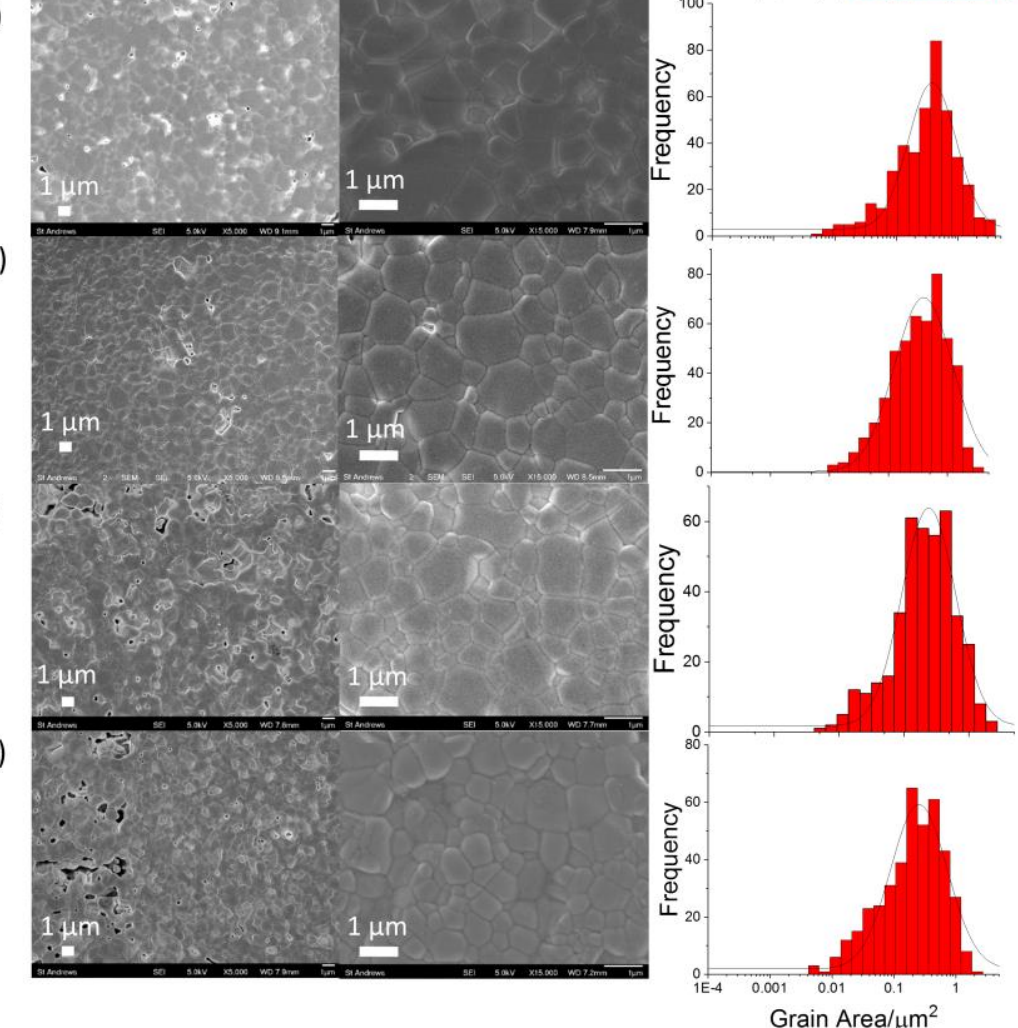

Figure 3. SEM images at intermediate and high magnification alongside log histograms showing the grain area distributions for samples sintered at $1450^{\circ} \mathrm{C}$ for $4 \mathrm{~h}:$ a) SDC, b) GDC, c) NDC, d), SG, e) SN, f) GN and g) SGN. 


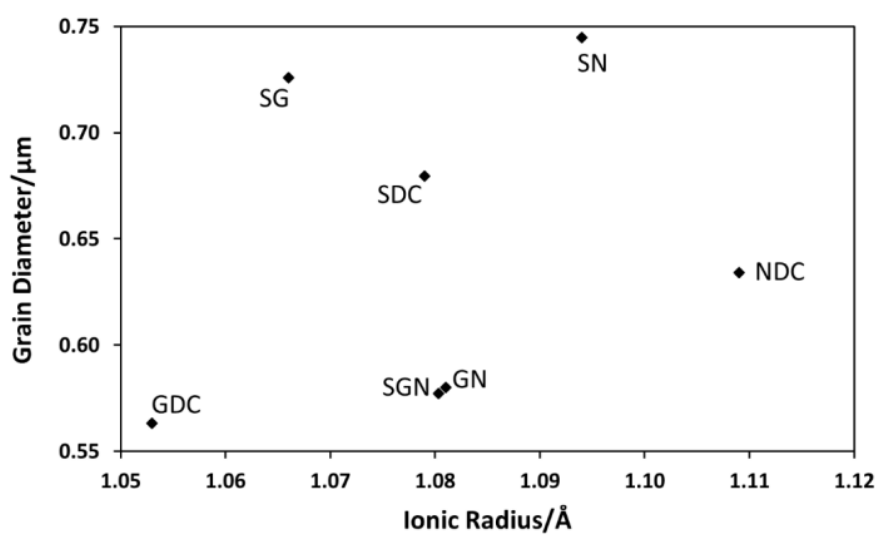

Figure 4. Average grain diameter (calculated from grain areas with the assumption that grain crosssections are circular) as a function of average ionic radius of dopant ions for $\mathrm{Ce}_{0.8} \mathrm{Sm}_{x} \mathrm{Gd}_{y} \mathrm{Nd}_{z} \mathrm{O}_{1.9}$ samples sintered at $1450^{\circ} \mathrm{C}$ for $4 \mathrm{~h}$.

\subsection{Electrical Properties}

Electronic conductivity was considered to be negligible under the oxidising conditions used in this work. Even at the highest temperature of $900{ }^{\circ} \mathrm{C}$ used to measure impedance where the reduction of ceria is most prevalent, the contribution to the total conductivity due to electronic conductivity is less than $1 \%$.[27],[28],[29],[30]

Impedance spectra are presented as Nyquist plots in Figure 5 for all seven compositions. At low temperatures (150 $400{ }^{\circ} \mathrm{C}$ ) two arcs are visible in the spectra. The higher frequency arc was assigned to bulk (intra-granular) ionic conduction and the smaller arc at lower frequency to ionic conduction across the grain boundaries (inter-granular). Total, bulk and grain boundary conductivities were calculated from the resistances acquired from the impedance spectra, the area of the Pt electrodes and the thickness of the electrolyte pellets. At intermediate $\left(450-550{ }^{\circ} \mathrm{C}\right)$ and high $\left(600-900^{\circ} \mathrm{C}\right)$ temperatures, the bulk arc was progressively obscured by the inductance of the apparatus and shifted above the operating frequency window of the spectrometer. Therefore, separate bulk and grain boundary conductivities were obtained from the spectra only for the lower temperatures, while total conductivities (bulk plus grain boundary) are given for all temperatures, since these could be obtained from the intercept with the $Z^{\prime}$ axis in the absence of the bulk arc. Values of capacitance were extracted from the fits to the Nqiust plots. At $300{ }^{\circ} \mathrm{C}$ values were very similar - at $0.95-1.1 \times 10^{-10} \mathrm{~F}-$ for the bulk arc and $2.1-4.9 \times 10^{-9} \mathrm{~F}$ for the grain boundary arc. Capacitances of around $10^{-6} \mathrm{~F}$ extracted from the main arc observed at high temperatures are characteristic of charge transfer 

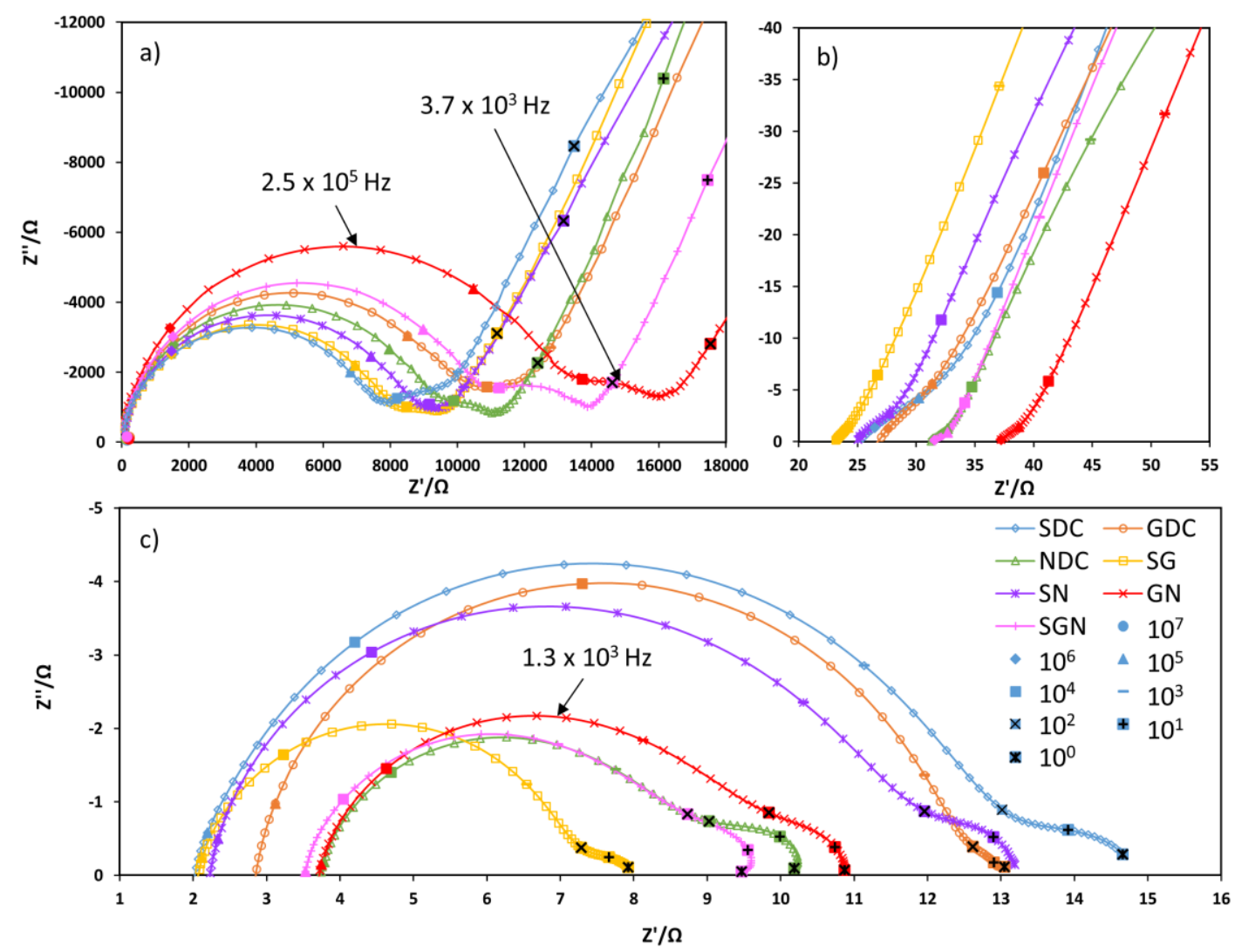

Figure 5. Nyquist plots for SDC, GDC, NDC, SG, SN, GN and SGN at a) $250^{\circ} \mathrm{C}$, b) $500^{\circ} \mathrm{C}$ and c) $750^{\circ} \mathrm{C}$.

Different symbols represent the change in frequency decade, the key for which is inset in panel (c).

processes at the electrode-electrolyte interface.[31] The smaller, low frequency arc at $750{ }^{\circ} \mathrm{C}$ can be assigned to electrode processes.

\subsubsection{Conductivities}

Figure 6 displays Arrhenius-type plots of the total, bulk and grain boundary conductivities for the SG sample, by way of example (plots for all seven samples are available as Figure S2 in the ESI). Grain boundary conductivity was much higher (by at least a factor of 4.5 ) than bulk conductivity for all of the compositions studied. Because of this, total conductivity was determined essentially by the bulk conductivity. This indicates that the materials synthesised in this work had low levels of impurities since these tend to accumulate at grain boundaries and have a particularly strong negative effect on grain boundary conductivity. Indeed, $\mathrm{Si}$ - the most problematic impurity in SOFC electrolyte materials - was found to be below the detection limits of 25 ppm in ICP-MS in the materials used in this study and below 10 ppm in XPS for multiply-doped cerias prepared in the same way (T. Sherwood, R.T. Baker, unpublished work). 


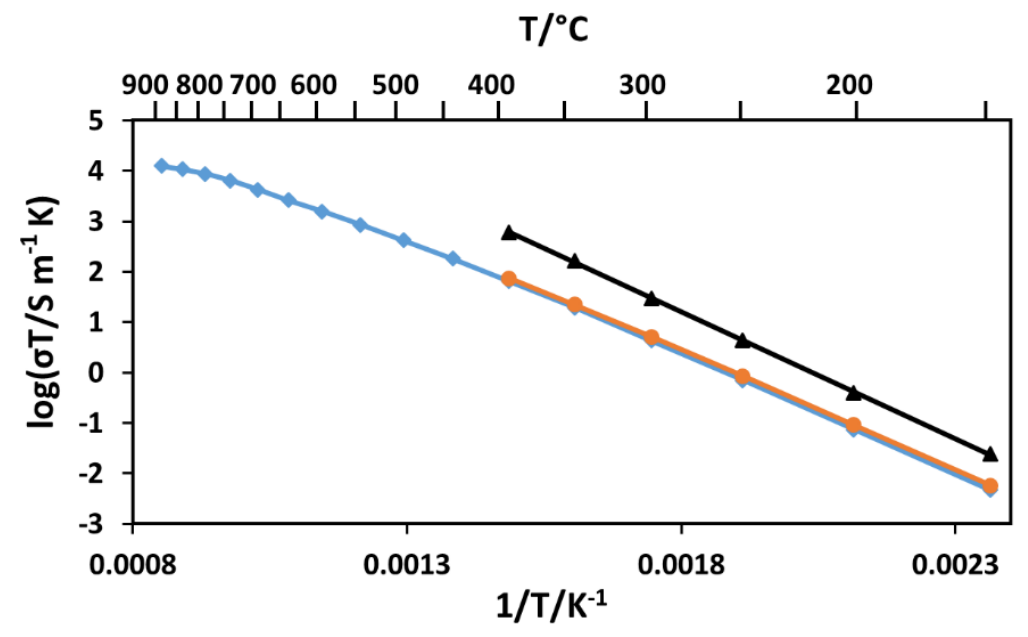

Figure 6. Arrhenius plots of total ( $\diamond)$, bulk ( $(\bullet)$ and grain boundary ( $\mathbf{\Delta})$ conductivity for SG.

In the log plots presented in Figure 7 it is possible to compare the total, bulk and grain boundary conductivities for all samples over a wide range of temperatures. Variations in total conductivity are the most significant. Grain boundary conductivity is generally very high - attributed to the high purity of these materials - and this leads to the close dependence seen of total conductivity on bulk conductivity. In all plots, a trough in conductivity occurs for the two samples containing both Gd and Nd dopants, SGN and GN. It may be significant that these dopants occupy the two extremes of ionic radius of the dopants studied here. In Figure 7(b), the bulk conductivity of SG overtakes that of SDC, to become the most conductive, as temperature increases. In Figure $7(a)$, this trend continues for total conductivity until SDC becomes dominant again at $800^{\circ} \mathrm{C}$.

In order to study more closely the differences between compositions, normalised bulk $\left(\sigma_{b}\right)$ and grain boundary $\left(\sigma_{\mathrm{gb}}\right)$ conductivities are plotted against temperature for all samples in Figure 8(a) and (b) and normalised total conductivity $\left(\sigma_{t}\right)$ is plotted in the same way in Figure $8(c)$. The normalisations were carried out by dividing each conductivity value by the corresponding value for the SDC sample at the same measurement temperature.

Bulk conductivity was highest for SDC between $150^{\circ} \mathrm{C}$ and $250^{\circ} \mathrm{C}$ and for $\mathrm{SG}$ from $300^{\circ} \mathrm{C}$ to $400^{\circ} \mathrm{C}$ and was lowest for $\mathrm{GDC}$ at $150{ }^{\circ} \mathrm{C}$ and for $\mathrm{GN}$ between $200{ }^{\circ} \mathrm{C}$ and $400{ }^{\circ} \mathrm{C}$. The presence of $\mathrm{Gd}$ appears to cause normalised $\sigma_{\mathrm{b}}$ to increase with temperature with respect to SDC, while $\mathrm{Nd}$ results in a decrease and where both are present the plot is roughly flat. 

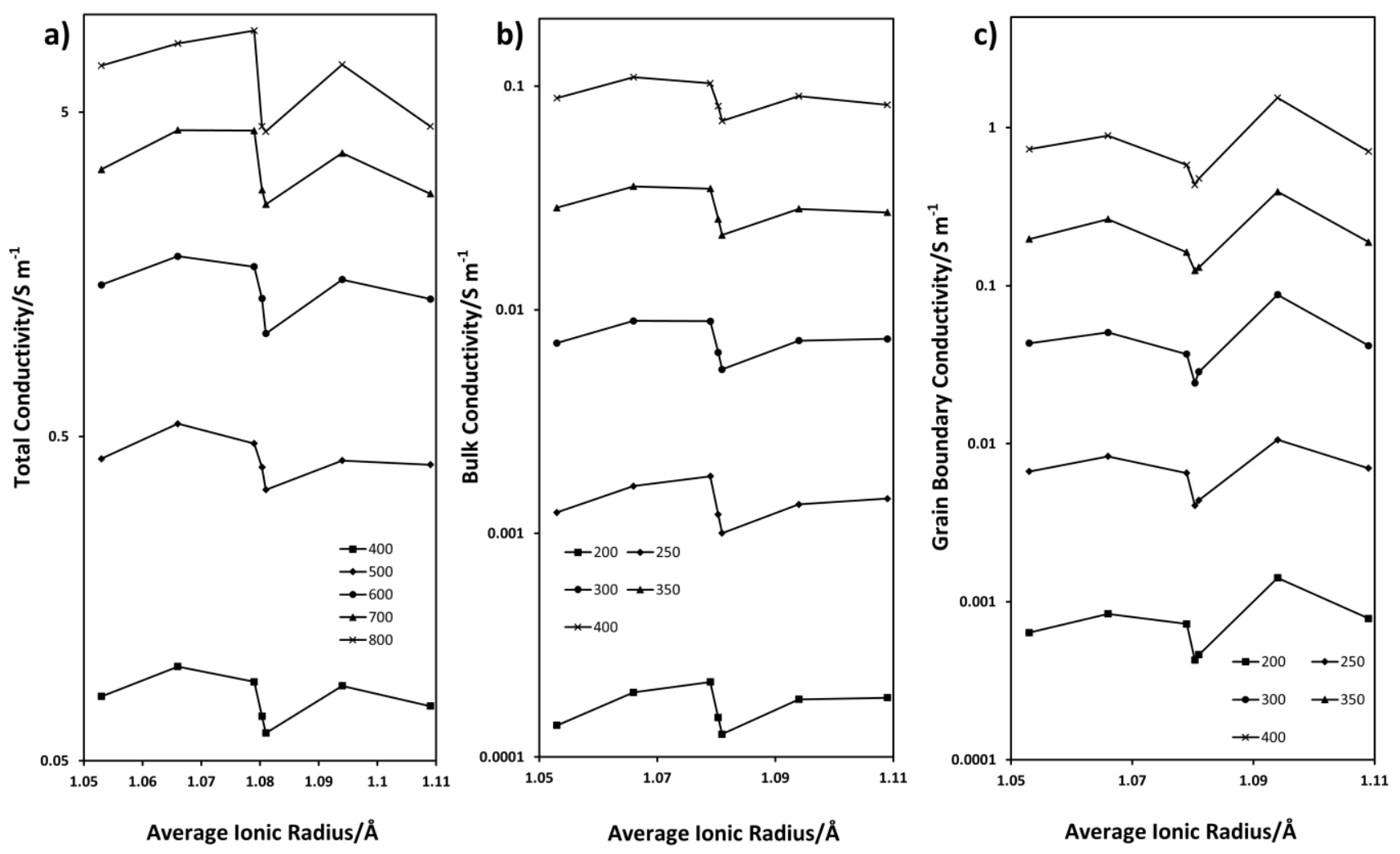

Figure 7. Log plots of (a) total, (b) bulk and (c) grain boundary conductivity as a function of average ionic radius for all samples.

In Figure $8(b)$, grain boundary conductivity was highest for $\mathrm{SN}$ at all temperatures for which $\sigma_{\mathrm{gb}}$ could be calculated, from $150{ }^{\circ} \mathrm{C}$ to $400{ }^{\circ} \mathrm{C}$. It was lowest for GDC at $150{ }^{\circ} \mathrm{C}$ and SGN from $200{ }^{\circ} \mathrm{C}$ to $400{ }^{\circ} \mathrm{C}$. The different sample compositions were in a very similar order to that seen for bulk conductivity. This suggests that intrinsic (bulk) conductivity is an important factor in $\sigma_{\mathrm{gb}}$. The main differences were that SN rose up the order, and SDC and SGN fell. These changes cannot be simply accounted for by considering the grain size and density of the samples. The relatively small size of the grain boundary arcs (and so the errors in fitting them) and the small variations seen in relative density and in grain diameter across the sample series make it difficult to interpret the differences in $\sigma_{\mathrm{gb}}$ values in terms of microstructural parameters. Also, the different chemical compositions are likely to have some direct effect on the properties of the grain boundaries.

The total conductivity of $1.67 \mathrm{~S} \mathrm{~m}^{-1}$ for SDC at $600{ }^{\circ} \mathrm{C}$ is very similar to the $1.81 \mathrm{~S} \mathrm{~m}^{-1}$ obtained by Kosinski and Baker for $\mathrm{Ce}_{0.8} \mathrm{Sm}_{0.2} \mathrm{O}_{1.9}$ at the same temperature although in this case a sintering time of $6 \mathrm{~h}$ was used.[24] However, it was higher than those of Balazs and co-workers of $1.2 \mathrm{~S} \mathrm{~m}^{-1}$ at $600{ }^{\circ} \mathrm{C}$ for $\mathrm{Ce}_{0.2} \mathrm{Sm}_{0.8} \mathrm{O}_{1.9}$ and of Zhan and co-workers for the same composition synthesised via traditional ceramic routes.[32]'[33] These lower conductivities are mostly due to 

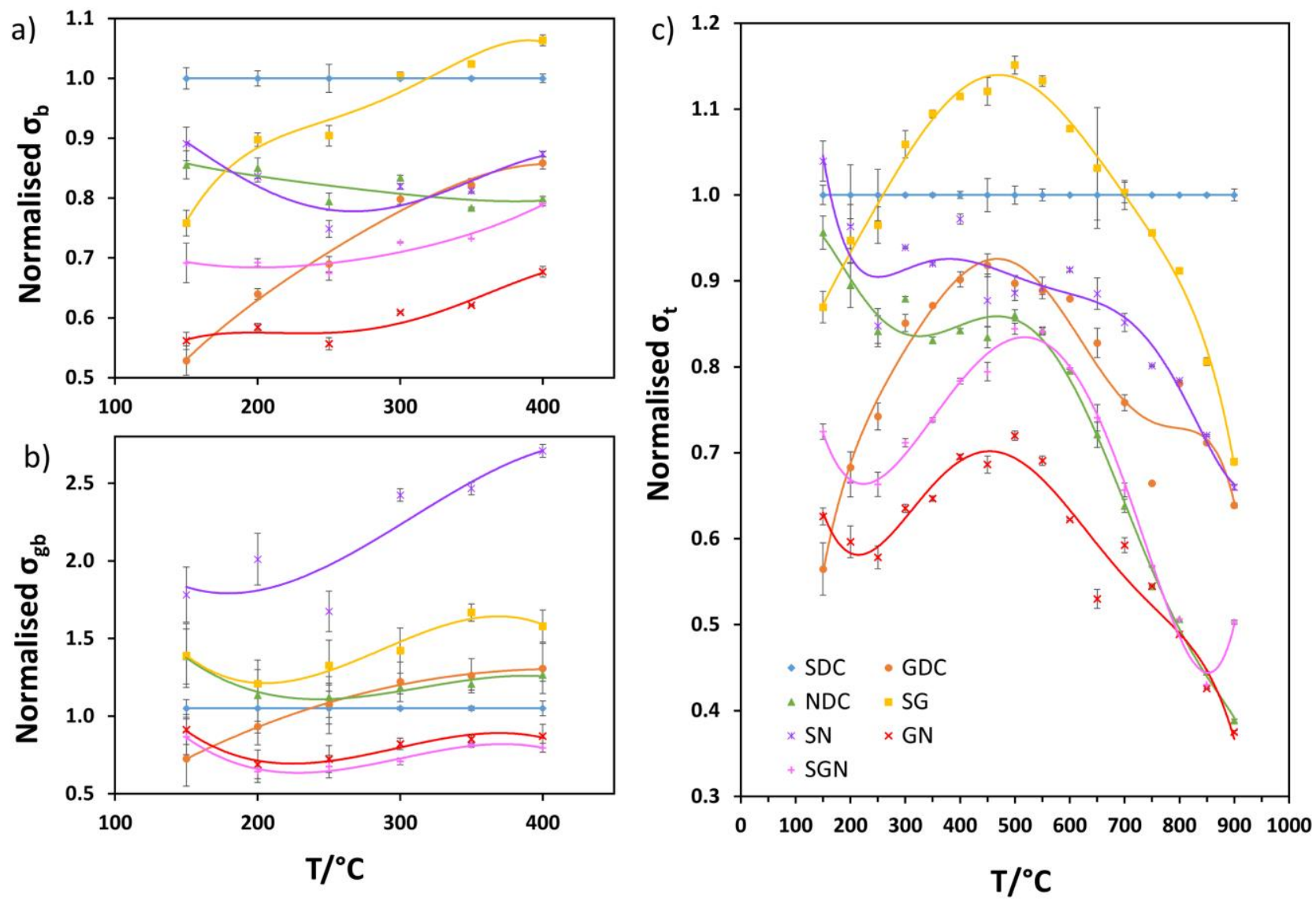

Figure 8. Plots of normalised (with respect to SDC) (a) bulk, (b) grain boundary and (c) total conductivity against measurement temperature for all samples.

lower grain boundary conductivities and these are linked to variations in preparation method and thus very probably to higher impurity levels, especially of $\mathrm{Si}$, in the cited studies. Van Herle and co-workers obtained total ionic conductivity values of $5-7 \mathrm{~S} \mathrm{~m}^{-1}$ at $750{ }^{\circ} \mathrm{C}$ in air for $\mathrm{Ce}_{0.2} \mathrm{M}_{0.8} \mathrm{O}_{1.9}(\mathrm{M}=\mathrm{Gd}$, Sm or $\mathrm{Y}$ ) electrolytes prepared by a coprecipitation method.[34] This is comparable to the values of $6.58 \mathrm{~S} \mathrm{~m}^{-1}$ (SDC) and $6.29 \mathrm{~S} \mathrm{~m}^{-1}$ (SG) obtained here at the same temperature although the value for GDC $\left(4.42 \mathrm{~S} \mathrm{~m}^{-1}\right)$ lies slightly below this range. The authors attributed their excellent ionic conductivity values to their high relative densities of around $97 \%$.

In Figure $8(\mathrm{c})$, normalised total conductivity, $\sigma_{\mathrm{t}}$, is plotted over the whole range of measurement temperature, from 150 to $900{ }^{\circ} \mathrm{C}$. At both 150 and $400^{\circ} \mathrm{C}$, the samples are arranged in the same order of increasing normalised $\sigma_{\mathrm{t}}$ as they were for $\sigma_{b}$ in Figure 8(a). This again indicates the relatively small effect of $\sigma_{\mathrm{gb}}$ on $\sigma_{\mathrm{t}}$ and therefore that $\sigma_{\mathrm{t}}$ is determined essentially by $\sigma_{b}$. GDC had the lowest total conductivity at $150{ }^{\circ} \mathrm{C}$, whereas $\mathrm{GN}$ was the lowest between $200{ }^{\circ} \mathrm{C}$ and $700{ }^{\circ} \mathrm{C}$ and between $800{ }^{\circ} \mathrm{C}$ and $900^{\circ} \mathrm{C}$ and NDC was lowest at $750^{\circ} \mathrm{C}$. The highest values of $\sigma_{t}$ were for SN at $150{ }^{\circ} \mathrm{C}$, 
for SDC at $200{ }^{\circ} \mathrm{C}$ and $250{ }^{\circ} \mathrm{C}$ and between $750{ }^{\circ} \mathrm{C}$ and $900{ }^{\circ} \mathrm{C}$ and for SG between $300{ }^{\circ} \mathrm{C}$ and $700{ }^{\circ} \mathrm{C}$. The fact that SG has a higher conductivity than SDC - a widely used SOFC electrolyte composition - over this wide range of temperatures is technologically important given the drive to reduce SOFC operating temperatures and to develop ITSOFCs for use between 500 and $700{ }^{\circ} \mathrm{C}$. These results imply that SG would be a better electrolyte than SDC (or GDC) for such devices. For this reason, the Sm-Gd system is the subject of an ongoing detailed study by the present authors.

The combination of $10 \mathrm{~mol} \%$ each of $\mathrm{Sm}^{3+}$ and $\mathrm{Gd}^{3+}$ is optimal for a $20 \mathrm{~mol} \%$ doped ceria electrolyte at intermediate temperatures. This may be due to this specific combination of ionic radii giving increased oxygen ion mobility at these temperatures due to an optimal balance between migration and association enthalpies (see later). This could arise from the way the equal mix of $\mathrm{Sm}^{3+}$ and $\mathrm{Gd}^{3+}$ dopant ions forms defect clusters and complexes and the kind of structures that form.

The samples containing $\mathrm{Nd}$ (including GN) show a peak at very low temperatures in Figure 8(c) while those containing Gd (except GN) instead exhibit a sharp increase in normalised $\sigma_{t}$ as temperature increased from its lowest value. This is a consequence of the increasing strengths of temperature dependence for $\mathrm{Nd}-<\mathrm{Sm}-<\mathrm{Gd}$ - containing samples which are reflected in the activation energies (see next section).

An important question in the field of SOFC electrolyte materials is whether co-doping results in detrimental, average or beneficial changes in conductivity with respect to the singly-doped, 'parent' materials. From Figure 8 , the conductivity of SG is significantly higher than the singly-doped compounds, SDC and GDC, between $300{ }^{\circ} \mathrm{C}$ and $700{ }^{\circ} \mathrm{C}$ (the upper end of which are feasible IT-SOFC working temperatures). The greatest enhancement is observed at $500{ }^{\circ} \mathrm{C}$ where $\sigma_{t}$ for SG is $15 \%$ higher than that for SDC and $28 \%$ higher than that for GDC. However, at the low and high extremes of the temperature scale, at $150-250{ }^{\circ} \mathrm{C}$ and $750-900{ }^{\circ} \mathrm{C}, \sigma_{t}$ for SG is intermediate between those of GDC and SDC. SN has $\sigma_{t}$ values intermediate between those of SDC and NDC between $200{ }^{\circ} \mathrm{C}$ and $900{ }^{\circ} \mathrm{C}$ indicating an averaging effect. However, normalised $\sigma_{t}$ for SN increases as temperature falls and is higher than for SDC or NDC (or any other sample) at $150{ }^{\circ} \mathrm{C}$. Co-doping to form GN has a clearly detrimental effect since $\sigma_{\mathrm{t}}$ is lower than either GDC or NDC from 200 to $700{ }^{\circ} \mathrm{C}$ and only roughly equal to the lower of these at $150{ }^{\circ} \mathrm{C}(\mathrm{GDC})$ and 800 to $900{ }^{\circ} \mathrm{C}$ (NDC). The behaviour of the triply-doped sample (SGN) is similar. Again, its $\sigma_{t}$ is lower than any of the three singly-doped materials at $250-500{ }^{\circ} \mathrm{C}$ but has similar values to the lowest of the three at $150{ }^{\circ} \mathrm{C}$ (GDC) and at $550-900{ }^{\circ} \mathrm{C}$ (NDC). Triple doping in this case is clearly detrimental. Taken overall, these results suggest that the conductivity of multiply-doped cerias 
cannot always be interpreted simply as an average of the conductivities of the singly-doped parent materials, as was concluded in the computational study of Burbano et al.[22]

Dikmen and co-workers also reported that co-doping can improve the electrical performance of ceria-based electrolytes.[35]'[36] The ionic conductivity of $\mathrm{Ce}_{0.8} \mathrm{Sm}_{0.18} \mathrm{Gd}_{0.02} \mathrm{O}_{1.9}\left(2.88 \mathrm{~S} \mathrm{~m}^{-1}\right)$ was found to be almost twice as high as that for singly-doped $\mathrm{Ce}_{0.8} \mathrm{Gd}_{0.2} \mathrm{O}_{1.9}\left(1.51 \mathrm{~S} \mathrm{~m}^{-1}\right)$, at $700{ }^{\circ} \mathrm{C}$.[35] In the present study a similar enhancement was seen. Total conductivities at the same temperature were $4.40 \mathrm{~S} \mathrm{~m}^{-1}$ for $\mathrm{SG}\left(\mathrm{Ce}_{0.8} \mathrm{Sm}_{0.1} \mathrm{Gd}_{0.1} \mathrm{O}_{1.9}\right)$ and $3.30 \mathrm{~S} \mathrm{~m}^{-1}$ for GDC. The fact that these values are higher can be attributed to the different synthesis methods (citrate complexation compared to hydrothermal) and the different Sm:Gd ratios in the co-doped samples. However, a further study by Dikmen gave a maximum conductivity value of $6.50 \mathrm{~S} \mathrm{~m}^{-1}$ for $\mathrm{Ce}_{0.8} \mathrm{Sm}_{0.1} \mathrm{Gd}_{0.1} \mathrm{O}_{1.9}$ at $700{ }^{\circ} \mathrm{C}$, which is approximately $50 \%$ higher than the value obtained here for the same composition and temperature.[36]

Kahlaoui and co-workers found that the total conductivity of the co-doped material, $\mathrm{Ce}_{0.8} \mathrm{Sm}_{0.1} \mathrm{Nd}_{0.1} \mathrm{O}_{1.9}$, was higher $3.29 \mathrm{~S} \mathrm{~m}^{-1}$ - than that of the singly-doped $\mathrm{Ce}_{0.8} \mathrm{Sm}_{0.2} \mathrm{O}_{1.9}-2.32 \mathrm{~S} \mathrm{~m}^{-1}-$ at $700{ }^{\circ} \mathrm{C}$, both samples having been made by the citric acid-nitrate process.[37] In the present study, however, SN was found to have a lower total conductivity than SDC apart from at low temperatures (see Figure 8), although the absolute values at $700{ }^{\circ} \mathrm{C}$ were much higher for SDC - $4.39 \mathrm{~S} \mathrm{~m}^{-1}$ - and slightly higher for $\mathrm{SN}-3.73 \mathrm{~S} \mathrm{~m}^{-1}$ - than those of Kahlaoui et al.[37] Thus, the higher conductivity of $\mathrm{Ce}_{0.8} \mathrm{Sm}_{0.1} \mathrm{Nd}_{0.1} \mathrm{O}_{1.9}$ synthesised by Kahlaoui et al compared to SDC may be due to an unusually low value for SDC.[37]

The highest total conductivity at $550{ }^{\circ} \mathrm{C}$ observed by Anirban and co-workers for the series of materials, $\mathrm{Ce}_{0.9} \mathrm{Gd}_{0.1-}$ ${ }_{x} \mathrm{Nd}_{x} \mathrm{O}_{1.95}(0 \leq x \leq 0.1)$ prepared by citrate-nitrate auto-ignition, was $6.82 \times 10^{-3} \mathrm{~S} \mathrm{~m}^{-1}$ when $x=0.075$, which is significantly lower than the value of $0.635 \mathrm{~S} \mathrm{~m}^{-1}$ obtained here for the co-doped sample, GN, at the same temperature.[20] This is likely to be due to both the difference in dopant ratios (although they also report a value of $1.96 \times 10^{-3} \mathrm{~S} \mathrm{~m}^{-1}$ at $550{ }^{\circ} \mathrm{C}$ for $x=0.05$ ) and the difference in total dopant concentration: $10 \%$ used by these authors and $20 \%$ in the current study.[20]

\subsubsection{Activation Energies}




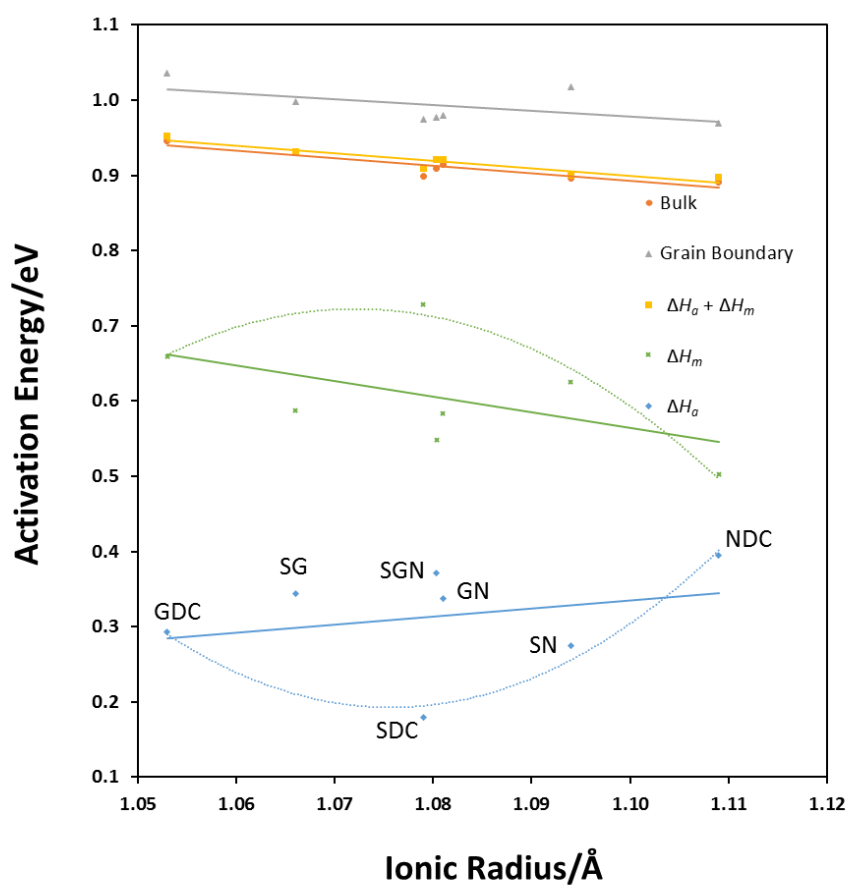

Figure 9. Activation energies for bulk and grain boundary processes and total conductivity below $\left(\Delta H_{m}+\Delta H_{a}\right)$ and above $\left(\Delta H_{m}\right) 450^{\circ} \mathrm{C}$ and $\Delta H_{a}$. The best fit lines are added as guides to the eye. See text for details.

In Figures 6 and S2, the plots of total conductivity contain a change in gradient at around $500{ }^{\circ} \mathrm{C}$. This is a general and well-known effect for ionically-conducting aliovalently-doped ceramics which was explained by Steele for GDC.[38] At low temperatures, below this inflection point, defect clusters of the type $V_{o}^{\prime \prime}-M_{C e}^{\prime}$ (and some $M_{C e}^{\prime}-V_{o}^{\prime \prime}-M_{C e}^{\prime}$ ), are expected to be common, especially at high dopant concentrations like the $20 \mathrm{~mol} \%$ value used here. These defect clusters dissociate progressively as temperature rises and above the inflection point it is assumed that no defect clusters remain, having all been thermally dissociated.. Therefore, at high temperatures, above the inflection point, we assume that the defect cluster concentration is insignificant and the gradient here can be equated to the migration enthalpy of the oxygen vacancies, $\Delta H_{m}$, alone whilst below the inflection - where defect clusters are common and trap oxygen vacancies - it is equal to migration enthalpy plus the defect association enthalpy, $\Delta H_{m}+\Delta H_{a}$. Thus, by obtaining gradients above and below the inflection point, values for $\Delta H_{m}$ and $\Delta H_{a}$ can be calculated. Values of $\Delta H_{m}$, $\Delta H_{a}, E_{t}=\Delta H_{m}+\Delta H_{a}$ (from the low temperature section of the $\sigma_{\mathrm{t}}$ plot) as well as activation energies for bulk and grain boundary conductivity were calculated. These are plotted as a function of average dopant ionic radius in Figure 9 and compared to literature values in Table 3. Values for the pre-exponential constant were obtained by extrapolating the low temperature branch of the Arrhenius plots to the $y$-axis and these are presented in Figure 10. 


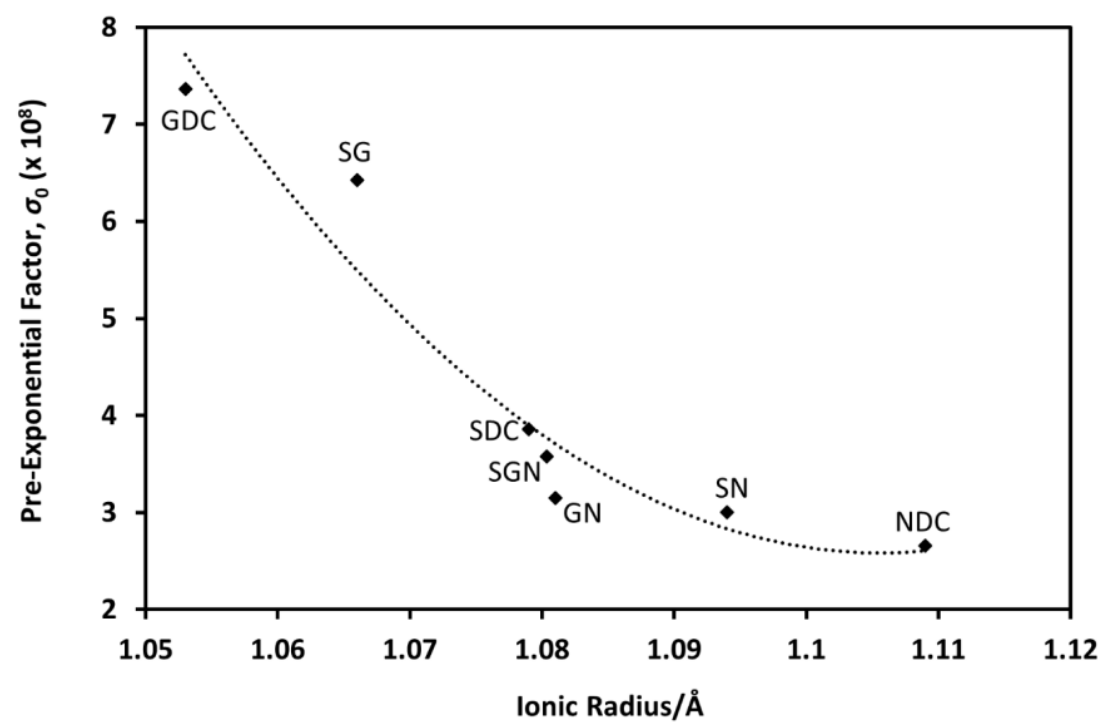

Figure 10. Variation of Pre-exponential constant, $\sigma_{o}$, with average ionic radius. The best fit line is added as a guide to the eye. See text for details.

The general trend for the activation energies for the bulk, grain boundary and total (below $500{ }^{\circ} \mathrm{C}, E_{t}$ ) conductivities is a close-to-linear, gradual decrease with increasing average dopant ionic radius. The pre-exponential constant shows a decrease with increasing average ionic radius. The value for SG appears to be slightly higher than this general trend (the best-fit line) - which would act to increase conductivity - while the values for SGN and GN are slightly below it. Activation energy values for total and bulk conductivity are very similar, while those for grain boundary conductivity are considerably higher. The activation energies for SDC are very close to those reported by Konsinski and Baker for $\mathrm{Ce}_{0.8} \mathrm{Sm}_{0.2} \mathrm{O}_{1.9}$ sintered under slightly different regimes.[24] The value of $E_{t}$ for SDC (0.91 eV) is close to that reported by Balazs $(0.85 \mathrm{eV})$ for the same composition. [32] Omar et al also found $E_{t}$ values decreased in singly doped ceria with increasing dopant radius to an approximate minimum for the Nd-doped material.[18]

The values of $\Delta H_{m}$ and $\Delta H_{a}$ show more scatter than those of $E_{t}$ in which they are combined. It is interesting to compare these plots with the work of Andersson et al who calculated values of $\Delta H_{a}$ and $\Delta H_{m}$ for ceria doped with lanthanides of atomic number, Z=57 (La) to 68 (Er).[14] Values for $\Delta H_{a}$ were obtained for two limiting cases in which dopant ions, $M_{C e}^{\prime}$, were (i) nearest neighbours (NN) or (ii) distant from each other (i.e. non-interacting). In each case, the electrostatic attraction (electronic interaction) and the lattice-mediated repulsion (elastic interaction) between the $M_{C e}^{\prime}$ and $V_{o}^{\prime \prime}$ species were calculated and summed. This was done for vacancies in NN and next-nearest neighbour (NNN) sites, relative to the dopant ions. For both limiting cases, (i) and (ii), the overall interaction energy favoured the 
NNN vacancy for lower Z (larger ions) and the NN position for the higher Z (smaller ions) with an energy minimum and cross-over between NN and NNN at $61(\mathrm{Pm})$ for case (i) and $62(\mathrm{Sm})$ for case (ii). The authors calculated a weighted average of the two cases corresponding to a dopant concentration of $4.2 \%$, added a constant value for bulk $\Delta H_{m}(\sim 0.5$ eV) and obtained a valley-shaped dependence on atomic number with an energy minimum at $Z=61 / 62$. The $\Delta H_{a}$ values were about $0.18,0.16,0,16$ and 0.21 for $\mathrm{Nd}, \mathrm{Pm}$ (and $\mathrm{Nd}: \mathrm{Sm}$ in a 1:1 ratio), Sm and Gd doping, respectively. At the higher doping level of $20 \%$ used in the present work these values would be expected to be higher - because of the larger contribution from dopants in the case (ii) configuration - but still be in a similar valley-like relationship. In Figure 9, the $\Delta H_{a}$ values of the corresponding compositions - GDC, SDC, SN and NDC - do seem to form such a dependence (see construction line). However, SG, GN and SGN do not, but have $\Delta H_{a}$ values similar to, or slightly higher than, those for GDC.

Turning now to the migration enthalpy, $\Delta H_{m}$, in the calculations just described, values were broadly similar to those found by Omar et al.[18] Andersson et al applied a constant value of $\Delta H_{m}$ which corresponded to vacancy migration distant from any dopant vacancies because of the low dopant concentration - $4.6 \%$ - that they considered. However, for a concentration of $20 \%$, migration will more frequently be close to dopant sites and the influence of these on migration enthalpy should be included. Fortunately, these authors considered the energetics of migrations between the different oxygen sites in the vicinity of dopant sites. Considering the NN and NNN sites for the vacancy, they again found a cross-over in the lowest enthalpy of migration as a function of atomic number at around $Z=62$. However, this time the relationship was a volcano curve with - near the centre - values of $\Delta H_{m}$ of about $0.38,0.40,0.39,0.33 \mathrm{eV}$ for doping with Nd, Pm, Sm and Gd, respectively. This should be treated with some caution as it was calculated for the dopant ions NN to each other only and also the present authors have not included other vacancy migrations of higher energy which are likely also to make some contribution. However, the values of $\Delta H_{m}$ for these same dopants - NDC, SDC, SN, GDC - in Figure 9 do show a volcano-type relationship with a maximum around SDC. As was seen for $\Delta H_{a}$, though, SG, GN and SGN do not fall on this curve (construction line).

Returning to the behaviour of the multiply doped samples in the present work, $\Delta H_{a}$ and $\Delta H_{m}$ values for GN and SN are averages of the values for their respective singly-doped parent compositions. Whereas Andersson et al used single (averaged) values of $Z$ and of ionic radius for doubly-doped compositions, the computational work of Minervini et al and Burbano et al indicated that different co-dopants tend to retain their local coordination environment in the ceria 
lattice.[14],[11]'[22] Burbano et al presented calculations for double doping in two combinations of a small and a large dopant ion, Sc-La and Sm-Nd. They concluded that these doubly-doped materials had conductivities and activation energies that were an average of those of the parent, singly-doped compositions. This may be the case in the present work for both $\Delta H_{m}$ and $\Delta H_{a}$ of SN and GN (note that SN fits both the averaging and the Andersson et al model). However, where Sm and Gd are present together - in SG and SGN - the activation energies do not fit this model. Perhaps two such small dopant ions disrupt each other's local environment via the host lattice more strongly competing for oxygen vacancies, for example - than a large and a small ion - whose coordination environments may be more complementary - especially at the relatively high dopant concentration used here (20\%).

Table 3 compares literature values for $\Delta H_{m}$ and $\Delta H_{a}$ with those obtained here. Omar and co-workers obtained an approximately constant value for $\Delta H_{a} \sim 0.05 \mathrm{eV}$ for $\mathrm{Ce}_{1-x} \mathrm{Sm}_{x / 2} \mathrm{Nd}_{x / 2} \mathrm{O}_{2-\delta}(x=0.08-0.18)$ and a $\Delta H_{m}$ of $0.80 \mathrm{eV}$ for $x=$ 0.18 , the highest value of $x$ used, which differ considerably from the respective values obtained here of 0.28 and 0.63 eV for SN.[16] These differences may have arisen from the different synthesis procedures used: citrate complexation vs. conventional solid state.[16] Kilner gave experimental and calculated values for $\Delta H_{a}$ of GDC of 0.13 and $0.17 \mathrm{eV}$, respectively.[8] The former agrees with that for GDC given by Steele.[38] These values are lower than those acquired here but the calculated value is closest to that for SDC. The computational calculations of Minervini and co-workers gave $\Delta H_{a}$ for GDC of $0.38 \mathrm{eV}$ (a little higher than the $0.29 \mathrm{eV}$ obtained here).[11] Faber and co-workers obtained $\Delta H_{a}$ values by extrapolating their data to infinite dopant dilution, with the assumption that $\Delta H_{m}$ was $0.5 \mathrm{eV}$.[39] The average $\Delta H_{m}$ obtained here is $0.60 \mathrm{eV}$, which is in line with general values given by Kilner and Steele $(0.6 \mathrm{eV})$ and Hohnke $(0.61 \mathrm{eV})$. [40][41] For $\mathrm{Nd}$ and $\mathrm{Gd}$ dopants, this gave $\Delta H_{a}$ values of 0.23 and $0.32 \mathrm{eV}$, respectively, which compare with values of 0.40 and $0.29 \mathrm{eV}$ acquired here for NDC and GDC, respectively, with $20 \%$ doping.

Poorly conducting grain boundaries would strongly affect total conductivity values, causing inaccuracies in the migration and association enthalpies acquired from them. However, this is not expected to be the case in this work as $\sigma_{\mathrm{gb}}$ was much higher than $\sigma_{\mathrm{b}}$. This is the result of using the solution-based nitrate-citrate synthesis method, which aids in decreasing impurity levels. This method is also expected to promote atomic mixing of the host (Ce) and dopant (Sm, $\mathrm{Gd}, \mathrm{Nd}$ ) cations whereas the ceramic method may lead to the production of nanodomains with different dopant concentrations due to its reliance on inter-diffusion of the starting oxides.

\section{Conclusions}


A citrate complexation process was used to prepare a series of $\mathrm{Ce}_{0.8} \mathrm{Sm}_{x} \mathrm{Gd}_{y} \mathrm{Nd}_{z} \mathrm{O}_{1.9}(x+y+z=0.2)$ nanopowders. Three singly-doped, $\mathrm{Ce}_{0.8} \mathrm{M}_{0.2} \mathrm{O}_{1.9}(\mathrm{M}=\mathrm{Sm}, \mathrm{Gd}, \mathrm{Nd})$, three doubly-doped, $\mathrm{Ce}_{0.8} \mathrm{M}_{0.1} \mathrm{M}_{0.1}^{\prime} \mathrm{O}_{1.9}\left(\mathrm{M} \neq \mathrm{M}^{\prime}=\mathrm{Sm}, \mathrm{Gd}, \mathrm{Nd}\right)$, and one triply-doped, $\mathrm{Ce}_{0.8} \mathrm{Sm}_{0.067} \mathrm{Gd}_{0.067} \mathrm{Nd}_{0.067} \mathrm{O}_{1.9}$, materials were prepared. These - and dense sintered pellets made from them - were used in a detailed study of the effect of multiple doping on microstructure and ionic conductivity with the central aim to investigate the effect of the chemical composition on electrical properties.

The nanopowders had crystallite sizes of 55 to $93 \AA$ and were high-purity, single-phase cubic fluorite materials which adhered to Vegard's Law. In the dense pellets, a general decrease in relative density with increasing average ionic radius of the dopant ion was observed. Average grain sizes showed no correlation with relative density or the average dopant ionic radius.

Impedance spectroscopy was carried out on the dense pellets. Grain boundary conductivity was much higher than bulk conductivity for all samples. This was linked to the low impurity contents achievable using the nitrate-citrate preparative method. Total conductivities of the singly-doped samples compared favourably with literature values.

Multiple doping was found to be detrimental (GN, SGN), averaging (SN) or beneficial (SG) compared to the singlydoped parent materials, depending on the combination of dopants present. There was some variation in these trends with temperature. These variations are attributed to the interplay between the activation energies of defect cluster association $\left(\Delta H_{a}\right)$ and oxygen ion migration $\left(\left(\Delta H_{m}\right)\right.$, and the pre-exponential factor.

SG had significantly higher total conductivity than GDC, SDC or any other sample at $300-700{ }^{\circ} \mathrm{C}$, having a value of 1.80 $\mathrm{S} \mathrm{m}^{-1}$ at $600^{\circ} \mathrm{C}$. This indicates that SG should be of considerable interest for application as an electrolyte in IT-SOFCs. The Sm-Gd system is the subject of an ongoing study.

Although no conductivity enhancing effect was observed for the triply doped compound (SGN) relative to the three singly doped parent compounds, to the best of the authors' knowledge this is the first time conductivity data for this combination of dopants has been reported.

Arrhenius-type plots of conductivity were used to obtain association and migration enthalpies and these had respective values of between $0.18(\mathrm{SDC})$ and $0.40 \mathrm{eV}(\mathrm{NDC})$ and between 0.50 (NDC) and $0.73 \mathrm{eV}(\mathrm{SDC})$. The trends in these enthalpies were discussed with reference to current models of doped cerias. For both association and migration enthalpies, connections to the computational model of Andersson et al is suggested for the singly-doped materials 
(and possibly SN), while for GN (and possibly SN) these appeared to be averages of the values for the corresponding singly-doped parent materials. This demonstrates the effect of ceria electrolyte chemical composition on electrical properties. Lastly, the values for the samples containing Sm and Gd together showed a further behaviour which was tentatively related to the small size of both ions and the possibility that they may disrupt each other's local environment in the host lattice more than a combination of a small and a large dopant ion, especially at the relatively high dopant concentration (20\%) used here.

\section{Acknowledgements}

The authors thank the University of St Andrews and the UK Engineering and Physical Sciences Research Council for the PhD studentship for AVC-A (grant code: EP/M506631/1). Electron microscopy was performed at the Electron Microscope Facility, University of St Andrews.

\section{References}

[1] Y. Guo, M. Bessaa, S. Aguado, M.C. Steil, D. Rembelski, M. Rieu, J.-P. Viricelle, N. Benameur, C. Guizard, C. Tardivat, P. Vernoux, D. Farrusseng, An all porous solid oxide fuel cell (SOFC): a bridging technology between dual and single chamber SOFCs, Energy Environ. Sci. 6 (2013) 2119-2123.

[2] E.D. Wachsman, C.A. Marlowe, K.T. Lee, Role of solid oxide fuel cells in a balanced energy strategy, Energy Environ. Sci. 5 (2012) 5498-5509.

[3] H. Qin, Z. Zhu, Q. Liu, Y. Jing, R. Raza, S. Imran, M. Singh, G. Abbas, B. Zhu, Direct biofuel low-temperature solid oxide fuel cells, Energy Environ. Sci. 4 (2011) 1273-1276.

[4] J.C. Ruiz-Morales, D. Marrero-López, M. Gálvez-Sánchez, J. Canales-Vázquez, C. Savaniu, S.N. Savvin, Engineering of materials for solid oxide fuel cells and other energy and environmental applications, Energy Environ. Sci. 3 (2010) 1670-1681.

[5] A.B. Stambouli, E. Traversa, Solid oxide fuel cells (SOFCs): a review of an environmentally clean and efficient source of energy, Renew. Sustain. Energy Rev. 6 (2002) 433-455.

[6] T. Ishii, Y. Tajima, Low Temperature Operation of Solid Oxide Fuel Cell with a $\mathrm{ZrO}_{2}-\mathrm{Sc}_{2} \mathrm{O}_{3}-\mathrm{Al}_{2} \mathrm{O}_{3} \mathrm{System}$ Electrolyte, J. Electrochem. Soc. 141 (1994) 3450-3453.

[7] Y. Mishima, H. Mitsuyasu, M. Ohtaki, K. Eguchi, Solid oxide fuel cell with composite electrolyte consisting of samaria-doped ceria and yttria-stabilised zirconia, J. Electrochem. Soc. 145 (1998) 1004-1007. 
[8] J. Kilner, Fast oxygen transport in acceptor doped oxides, Solid State lonics. 129 (2000) 13-23.

[9] H.L. Tuller, A.S. Nowick, Doped ceria as a solid oxide electrolyte, J. Electrochem. Soc. 122 (1975) 255-259.

[10] H. Inaba, H. Tagawa, Ceria-based solid electrolytes, Solid State lonics. 83 (1996) 1-16.

[11] L. Minervini, M.O. Zacate, R.W. Grimes, Defect cluster formation in $\mathrm{M}_{2} \mathrm{O}_{3}$-doped $\mathrm{CeO}_{2}$, Solid State lonics. 116 (1999) 339-349.

[12] R. Shannon, Revised effective ionic radii and systematic studies of interatomic distances in halides and chalcogenides, Acta Crystallogr. Sect. A. 32 (1976) 751-767.

[13] M. Mogensen, D. Lybye, N. Bonanos, P. V. Hendriksen, F.W. Poulsen, Factors controlling the oxide ion conductivity of fluorite and perovskite structured oxides, Solid State lonics. 174 (2004) 279-286.

[14] D.A. Andersson, S.I. Simak, N. V. Skorodumova, I.A. Abrikosov, B. Johansson, Optimization of ionic conductivity in doped ceria., Proc. Natl. Acad. Sci. U. S. A. 103 (2006) 3518-3521.

[15] I. Stephens, J. Kilner, Ionic conductivity of $\mathrm{Ce}_{1-x} \mathrm{Nd}_{x} \mathrm{O}_{2-x / 2}$, Solid State Ionics. 177 (2006) 669-676.

[16] S. Omar, E. Wachsman, J. Nino, Higher conductivity $\mathrm{Sm}^{3+}$ and $\mathrm{Nd}^{3+}$ co-doped ceria-based electrolyte materials, Solid State Ionics. 178 (2008) 1890-1897.

[17] S. Omar, E. Wachsman, J. Nino, A co-doping approach towards enhanced ionic conductivity in fluorite-based electrolytes, Solid State Ionics. 177 (2006) 3199-3203.

[18] S. Omar, E.D. Wachsman, J.L. Jones, J.C. Nino, Crystal Structure-lonic Conductivity Relationships in Doped Ceria Systems, J. Am. Ceram. Soc. 92 (2009) 2674-2681.

[19] F.-Y. Wang, B.-Z. Wan, S. Cheng, Study on $\mathrm{Gd}^{3+}$ and Sm${ }^{3+}$ co-doped ceria-based electrolytes, J. Solid State Electrochem. 9 (2004) 168-173.

[20] S. Anirban, T. Paul, P.T. Das, T.K. Nath, A. Dutta, Microstructure and electrical relaxation studies of chemically derived Gd-Nd co-doped nanocrystalline ceria electrolytes, Solid State lonics. 270 (2015) 73-83.

[21] Y. Liu, B. Li, X. Wei, W. Pan, Citric-nitrate combustion synthesis and electrical conductivity of the $\mathrm{Sm}^{3+}$ and $\mathrm{Nd}^{3+}$ co-doped ceria electrolyte, J. Am. Ceram. Soc. 91 (2008) 3926-3930.

[22] M. Burbano, S. Nadin, D. Marrocchelli, M. Salanne, G.W. Watson, Ceria co-doping: synergistic or average effect?, Phys. Chem. Chem. Phys. 16 (2014) 8320-8331.

[23] R.O. Fuentes, R.T. Baker, Structural, morphological and electrical properties of $\mathrm{Gd}_{0.1} \mathrm{Ce}_{0.9} \mathrm{O}_{1.95}$ prepared by a citrate complexation method, J. Power Sources. 186 (2009) 268-277. 
[24] M.R. Kosinski, R.T. Baker, Preparation and property-performance relationships in samarium-doped ceria nanopowders for solid oxide fuel cell electrolytes, J. Power Sources. 196 (2011) 2498-2512.

[25] A.R. Denton, N.W. Ashcroft, Vegards law, Phys. Rev. A. 43 (1991) 3161-3164.

[26] H. Klug, L. Alexander, X-Ray Diffraction Procedures for Polycrystalline and Amorphous Materials, John Wiley, New York, 1974.

[27] T.H. Kwon, T. Lee, H.I. Yoo, Partial electronic conductivity and electrolytic domain of bilayer electrolyte $\mathrm{Zr}_{0.84} \mathrm{Y}_{0.16} \mathrm{O}_{1.92} / \mathrm{Ce}_{0.9} \mathrm{Gd}_{0.1} \mathrm{O}_{1.95}$, Solid State Ionics. 195 (2011) 25-35.

[28] K.R. Lee, J.H. Lee, H.I. Yoo, Reassessment of conventional polarization technique to measure partial electronic conductivity of electrolytes, Solid State Ionics. 181 (2010) 724-729.

[29] T. Shimonosono, Y. Hirata, Y. Ehira, S. Sameshima, T. Horita, H. Yokokawa, Electronic conductivity measurement of Sm- And La-doped ceria ceramics by Hebb-Wagner method, Solid State lonics. 174 (2004) 27-33.

[30] T. Shimonosono, Y. Hirata, S. Sameshima, T. Horita, Electronic conductivity of La-doped ceria ceramics, J. Am. Ceram. Soc. 88 (2005) 2114-2120.

[31] J.T.S. Irvine, D.C. Sinclair, A.R. West, Electroceramics: characterization by impedance spectroscopy, Adv. Mater. 2 (1990) 132-138.

[32] G.B. Balazs, R.S. Glass, ac impedance studies of rare earth oxide doped ceria, Solid State lonics. 76 (1995) 155-162.

[33] Z. Zhan, T.-L. Wen, H. Tu, Z.-Y. Lu, AC Impedance Investigation of Samarium-Doped Ceria, J. Electrochem. Soc. 148 (2001) A427-A432.

[34] J. Van Herle, M. Dokiya, T. Horita, T. Kawada, N. Sakai, H. Yokokawa, Low temperature fabrication of (Y, Gd, Sm)-doped ceria electrolyte, Solid State Ionics. 86-88 (1996) 1255-1258.

[35] S. Dikmen, H. Aslanbay, E. Dikmen, O. Şahin, Hydrothermal preparation and electrochemical properties of $\mathrm{Gd}^{3+}$ and $\mathrm{Bi}^{3+}, \mathrm{Sm}^{3+}, \mathrm{La}^{3+}$, and $\mathrm{Nd}^{3+}$ codoped ceria-based electrolytes for intermediate temperature-solid oxide fuel cell, J. Power Sources. 195 (2010) 2488-2495.

[36] S. Dikmen, Effect of co-doping with $\mathrm{Sm}^{3+}, \mathrm{Bi}^{3+}, \mathrm{La}^{3+}$, and $\mathrm{Nd}^{3+}$ on the electrochemical properties of hydrothermally prepared gadolinium-doped ceria ceramics, J. Alloys Compd. 491 (2010) 106-112.

[37] M. Kahlaoui, S. Chefi, A. Inoubli, A. Madani, C. Chefi, Synthesis and electrical properties of co-doping with 
$\mathrm{La}^{3+}, \mathrm{Nd}^{3+}, \mathrm{Y}^{3+}$, and $\mathrm{Eu}^{3+}$ citric acid-nitrate prepared samarium-doped ceria ceramics, Ceram. Int. 39 (2013) 3873-3879.

[38] B.C.H. Steele, Appraisal of $\mathrm{Ce}_{1-y} \mathrm{Gd}_{y} \mathrm{O}_{2-y / 2}$ electrolytes for IT-SOFC operation at $500{ }^{\circ} \mathrm{C}$, Solid State lonics. 129 (2000) 95-110.

[39] J. Faber, C. Geoffroy, A. Roux, A. Sylvestre, P. Abelard, A systematic investigation of the dc-electrical conductivity of rare-earth-doped ceria, Appl. Phys. A. 49 (1989) 225-232.

[40] J.A. Kilner, B.C.H. Steele, Non-stoichiometric Oxides, Academic Press, New York, 1981.

[41] D.K. Hohnke, lonic conduction in doped oxides with the fluorite structure, Solid State lonics. 5 (1981) 531534.

[42] D. Pérez-Coll, P. Núñez, J.R. Frade, Improved conductivity of $\mathrm{Ce}_{[1-x]} \mathrm{Sm}_{[x]} \mathrm{O}_{[2-\delta]}$ ceramics with submicrometer grain sizes, J. Electrochem. Soc. 153 (2006) A478-A483.

[43] S. Ramesh, V.P. Kumar, P. Kistaiah, C.V. Reddy, Preparation, characterization and thermo electrical properties of co-doped $\mathrm{Ce}_{0.8-x} \mathrm{Sm}_{0.2} \mathrm{Ca}_{x} \mathrm{O}_{2-\delta}$ materials, Solid State lonics. 181 (2010) 86-91.

[44] X. Sha, Z. Lü, X. Huang, J. Miao, L. Jia, X. Xin, W. Su, Preparation and properties of rare earth co-doped $\mathrm{Ce}_{0.8} \mathrm{Sm}_{0.2-x} \mathrm{Y}_{x} \mathrm{O}_{1.9}$ electrolyte materials for SOFC, J. Alloys Compd. 424 (2006) 315-321.

[45] D. Perez-Coll, D. Marrero-Lopez, P. Nunez, S. Pinol, J.R. Frade, Grain boundary conductivity of $\mathrm{Ce}_{0.8} \mathrm{Ln}_{0.2} \mathrm{O}_{2-\delta}$ ceramics (Ln = Y, La, Gd, Sm) with and without co-doping, Electrochim. Acta. 51 (2006) 6463-6469.

[46] Y.P. Fu, S.H. Chen, J.J. Huang, Preparation and characterization of $\mathrm{Ce}_{0.8} \mathrm{M}_{0.2} \mathrm{O}_{2-\delta}(\mathrm{M}=\mathrm{Y}, \mathrm{Gd}, \mathrm{Sm}, \mathrm{Nd}$, La) solid electrolyte materials for solid oxide fuel cells, Int. J. Hydrogen Energy. 35 (2010) 745-752. 


\section{$\underline{\text { Tables }}$}

Table 1. Lattice parameters, $a$, unit cell volumes, $V$ and crystallite sizes as calculated by the Scherrer equation from powder XRD data, $D_{X R D}$ and as measured from TEM images, $D_{T E M}$, for $\mathrm{Ce}_{0.8} \mathrm{Sm}_{x} \mathrm{Gd}_{y} \mathrm{Nd}_{z} \mathrm{O}_{1.9}$ powders calcined at $500{ }^{\circ} \mathrm{C}$ for $2 \mathrm{~h}$.

\begin{tabular}{cccccc}
\hline Formula & Notation & $a / \AA$ & $V / \AA{ }^{3}$ & $D_{X N D} / \AA$ & $D_{\text {TEM }} / \AA$ \\
\hline $\mathrm{Ce}_{0.8} \mathrm{Sm}_{0.2} \mathrm{O}_{1.9}$ & $\mathrm{SDC}$ & $5.4323 \pm 0.0002$ & $160.31 \pm 0.02$ & $67 \pm 1.0$ & $75 \pm 18$ \\
$\mathrm{Ce}_{0.8} \mathrm{Gd}_{0.2} \mathrm{O}_{1.9}$ & $\mathrm{GDC}$ & $5.4244 \pm 0.0001$ & $159.61 \pm 0.01$ & $93 \pm 2.0$ & $109 \pm 32$ \\
$\mathrm{Ce}_{0.8} \mathrm{Nd}_{0.2} \mathrm{O}_{1.9}$ & $\mathrm{NDC}$ & $5.4446 \pm 0.0004$ & $161.40 \pm 0.04$ & $55 \pm 0.5$ & $81 \pm 37$ \\
$\mathrm{Ce}_{0.8} \mathrm{Sm}_{0.1} \mathrm{Gd}_{0.1} \mathrm{O}_{1.9}$ & $\mathrm{SG}$ & $5.4279 \pm 0.0002$ & $159.92 \pm 0.02$ & $77 \pm 1.5$ & $95 \pm 25$ \\
$\mathrm{Ce}_{0.8} \mathrm{Sm}_{0.1} \mathrm{Nd}_{0.1} \mathrm{O}_{1.9}$ & $\mathrm{SN}$ & $5.4410 \pm 0.0006$ & $161.08 \pm 0.05$ & $69 \pm 1.0$ & $83 \pm 8$ \\
$\mathrm{Ce}_{0.8} \mathrm{Gd}_{0.1} \mathrm{Nd}_{0.1} \mathrm{O}_{1.9}$ & $\mathrm{GN}$ & $5.4352 \pm 0.0003$ & $160.56 \pm 0.03$ & $72 \pm 1.0$ & $95 \pm 23$ \\
$\mathrm{Ce}_{0.8} \mathrm{Sm}_{0.2 / 3} \mathrm{Gd}_{0.2 / 3} \mathrm{Nd}_{0.2 / 3} \mathrm{O}_{1.9}$ & $\mathrm{SGN}$ & $5.4342 \pm 0.0003$ & $160.48 \pm 0.03$ & $63 \pm 1.0$ & $89 \pm 21$ \\
\hline
\end{tabular}


Table 2. Concentrations of cations as determined by ICP-MS for all powder samples. Errors are \pm one standard deviation.

\begin{tabular}{ccccc}
\hline Sample & Ce (cation \%) & Sm (cation \%) & Gd (cation \%) & Nd (cation \%) \\
\hline SDC & $78.3 \pm 2.0$ & $20.9 \pm 0.5$ & $0.70 \pm 0.02$ & $0.045 \pm 0.001$ \\
GDC & $77.1 \pm 5.1$ & $0.074 \pm 0.005$ & $22.8 \pm 1.5$ & $0.0132 \pm 0.0009$ \\
NDC & $77.7 \pm 7.5$ & $0.016 \pm 0.002$ & $0.75 \pm 0.07$ & $21.6 \pm 2.1$ \\
SG & $77.8 \pm 3.0$ & $10.5 \pm 0.4$ & $11.7 \pm 0.5$ & $0.027 \pm 0.001$ \\
SN & $78.3 \pm 1.2$ & $10.7 \pm 0.2$ & $0.67 \pm 0.01$ & $10.3 \pm 0.2$ \\
GN & $78.6 \pm 5.4$ & $0.021 \pm 0.001$ & $11.4 \pm 0.8$ & $10.0 \pm 0.7$ \\
SGN & $78.4 \pm 1.3$ & $6.9 \pm 0.1$ & $7.9 \pm 0.1$ & $6.7 \pm 0.1$ \\
\hline
\end{tabular}


Table 3: Comparison of the activation energy and association and migration enthalpy values obtained in this study with those reported in the literature for equivalent samples where possible. Where the literature composition is known and is different from that of this study, it is indicated.

\begin{tabular}{|c|c|c|c|c|c|c|c|c|c|c|}
\hline \multirow[b]{2}{*}{ Sample } & \multicolumn{6}{|c|}{ Activation Energy/eV } & \multirow{2}{*}{$\begin{array}{c}\text { Migration } \\
\text { Enthalpy/ } \\
\text { eV }\end{array}$} & \multirow{2}{*}{$\begin{array}{c}\text { Migration Enthalpy } \\
\text { (literature)/eV }\end{array}$} & \multirow{2}{*}{$\begin{array}{l}\text { Association } \\
\text { Enthalpy/eV }\end{array}$} & \multirow{2}{*}{$\begin{array}{c}\text { Association Enthalpy } \\
\text { (literature)/eV }\end{array}$} \\
\hline & Bulk & $\begin{array}{c}\text { Bulk } \\
\text { (literature) }\end{array}$ & $\begin{array}{l}\text { Grain } \\
\text { Boundary }\end{array}$ & $\begin{array}{c}\text { Grain Boundary } \\
\text { (literature) }\end{array}$ & Total $\left(\leq 450^{\circ} \mathrm{C}\right)$ & Total (literature) & & & & \\
\hline SDC & 0.90 & $0.85[42]$ & 0.98 & $0.94[43]$ & 0.91 & $0.85[32]$ & 0.73 & $0.69[44]$ & 0.18 & $\begin{array}{c}0.26[42] \\
0.17 \text { (calculated) and } 0.13 \\
\text { (experimental) [8], } 0.13\end{array}$ \\
\hline GDC & 0.95 & $0.94[45]$ & 1.04 & - & 0.95 & $0.75[46]$ & 0.66 & - & 0.29 & $\begin{array}{c}\left(\mathrm{Ce}_{0.9} \mathrm{Sm}_{0.1} \mathrm{O}_{1.95}\right) \text { [38], 0.32 } \\
\text { (composition unknown) [39], } 0.38 \\
\text { (composition unknown) [11] }\end{array}$ \\
\hline NDC & 0.89 & - & 0.97 & - & 0.90 & $0.78[32]$ & 0.50 & - & 0.40 & 0.23 (composition unknown) [39] \\
\hline SG & 0.93 & - & 1.00 & - & 0.93 & $0.59[36]$ & 0.59 & $\begin{array}{c}- \\
0.80\end{array}$ & 0.34 & - \\
\hline SN & 0.90 & $0.93[37]$ & 1.02 & $0.90[37]$ & 0.90 & $0.92[37]$ & 0.63 & $\begin{array}{c}\left(\mathrm{Ce}_{0.82} \mathrm{Sm}_{0.09} \mathrm{Nd}_{0.09} \mathrm{O}_{2-}\right. \\
\left.{ }_{\delta}\right)[16]\end{array}$ & 0.28 & $\sim 0.05\left(\mathrm{Ce}_{0.82} \mathrm{Sm}_{0.09} \mathrm{Nd}_{0.09} \mathrm{O}_{2-\delta}\right)[16]$ \\
\hline & & & & & & 0.98 & & & & \\
\hline GN & 0.92 & - & 0.98 & - & 0.92 & $\begin{array}{c}\left(\mathrm{Ce}_{0.9} \mathrm{Gd}_{0.05} \mathrm{Nd}_{0.05} \mathrm{O}_{1.95}\right) \\
{[20]}\end{array}$ & 0.58 & - & 0.34 & - \\
\hline SGN & 0.91 & - & 0.98 & - & 0.92 & - & 0.55 & - & 0.37 & - \\
\hline
\end{tabular}




\section{Figure Captions}

Figure 1. XRD patterns for powder samples of $\mathrm{Ce}_{0.8} \mathrm{Sm}_{x} \mathrm{Gd}_{y} \mathrm{Nd}_{z} \mathrm{O}_{1.9}$ for all compositions. *Small peak at about $45^{\circ}$ is due to the sample holder (main peak of Fe).

Figure 2. Dependence on average ionic radius of dopant ions in $\mathrm{Ce}_{0.8} \mathrm{Sm}_{x} \mathrm{Gd}_{y} \mathrm{Nd}_{z} \mathrm{O}_{1.9}$ of a) lattice parameter obtained from powder XRD; b) average crystallite size calculated from powder XRD data and TEM images; c) relative density of pellets sintered at $1450^{\circ} \mathrm{C}$ for $4 \mathrm{~h}$. The best fit lines are added as guides to the eye.

Figure 3. SEM images at intermediate and high magnification alongside log histograms showing the grain area distributions for samples sintered at $1450^{\circ} \mathrm{C}$ for $4 \mathrm{~h}$ : a) SDC, b) GDC, c) NDC, d), SG, e) SN, f) GN and g) SGN..

Figure 4. Average grain diameter (calculated from grain areas with the assumption that grain cross-sections are circular) as a function of average ionic radius of dopant ions for $\mathrm{Ce}_{0.8} \mathrm{Sm}_{x} \mathrm{Gd}_{y} \mathrm{Nd}_{z} \mathrm{O}_{1.9}$ samples sintered at $1450^{\circ} \mathrm{C}$ for $4 \mathrm{~h}$. The best fit line is added as a guide to the eye.

Figure 5. Nyquist plots for SDC, GDC, NDC, SG, SN, GN and SGN at a) $250^{\circ} \mathrm{C}$, b) $500^{\circ} \mathrm{C}$ and c) $750^{\circ} \mathrm{C}$. Different symbols represent the change in frequency decade, the key for which is inset in panel (c).

Figure 6. Arrhenius plots of total ( () , bulk ( $(\bullet)$ and grain boundary $(\mathbf{\Delta})$ conductivity for SG.

Figure 7. Log plots of (a) total, (b) bulk and (c) grain boundary conductivity against average ionic radius for all samples.

Figure 8. Plots of normalised (with respect to SDC) (a) bulk, (b) grain boundary and (c) total conductivity against measurement temperature for all samples.

Figure 9. Activation energies for bulk and grain boundary processes and total conductivity below $\left(\Delta H_{m}+\Delta H_{a}\right)$ and above $\left(\Delta H_{m}\right) 450{ }^{\circ} \mathrm{C}$ and $\Delta H_{a}$. The best fit lines are added as guides to the eye. See text for details.

Figure 10. Variation of Pre-exponential constant, $\sigma_{\boldsymbol{o}}$, with average ionic radius. The best fit line is added as a guide to the eye. See text for details. 